\title{
Residence- and source-based capital taxation in open economies with infinitely-lived consumers
}

\author{
Till Gross* \\ Carleton University \\ Paul Klein ${ }^{\dagger}$ \\ Stockholm University \\ Miltiadis Makris ${ }^{\ddagger}$ \\ University of Kent
}

June 17, 2020

\begin{abstract}
In this paper we investigate tax competition in a neoclassical growth model where each country may use both residence- and source-based capital taxes. We show that both types of capital taxes are zero at any interior steady state, just as in a closed economy. For symmetric countries, and even for countries that differ only with respect to size and productivity, we prove analytically and verify numerically that the open-economy policies coincide exactly with the closed-economy policies in all time periods. For countries that are asymmetric in other dimensions, we find that source-based taxes are used to manipulate the intertemporal terms of trade in the short run. Either way, the fiscal externalities of source-based taxes vanish once residence-based taxes are allowed.

JEL Classification: H21, E62

Keywords: Residence Principle, Capital Tax Competition, Dynamic Optimal Taxation, Open Economy, Ramsey Taxation
\end{abstract}

*Mailing address: Department of Economics, Carleton University, C-870 Loeb Building, 1125 Colonel By Drive, Ottawa, ON K1S 5B6, Canada. Email: till.gross@carleton.ca. This research was supported by the Social Sciences and Humanities Research Council of Canada.

${ }^{\dagger}$ Mailing Address: Department of Economics, Stockholm University, SE-10691 Stockholm, Sweden. Email: paul.klein@ne.su.se.

${ }^{\ddagger}$ Mailing Address: School of Economics, University of Kent, Canterbury, CT2 7FS, United Kingdom. Email: mmakris.econ@gmail.com. 


\section{Introduction}

Capital has become increasingly mobile between countries. This poses potentially large problems for the taxation of capital, since a high tax on capital may lead to capital flight to a country where the tax rate is lower. The risk of capital flight may be even more severe when tax authorities rely mainly on source-based capital taxes, such as corporate income taxes and withholding taxes; this will inevitably be the case if information about capital income is not shared across jurisdictions. Concerns over such "harmful tax competition" have been voiced, for instance, in communiqués by the OECD (1998) and the European Union (2003).

However, recent agreements on information sharing between OECD and EU countries make it more feasible to levy capital taxes according to the residence principle. In particular, the Common Reporting Standard ${ }^{1}$ is now being implemented, allowing for automatic information sharing between governments. This represents a major shift in the enforceability of residence-based capital taxes, making it more important than ever to understand the non-cooperative use of capital taxes by governments who can deploy both residence- and source-based taxes in the presence of capital mobility. The question we address here is the following: what is the effect of capital market integration on capital taxes when governments can tax according to the residence as well as the source principle?

We address this issue in the context of a multi-country neoclassical growth model with an infinite horizon. Our choice of a fully dynamic model with endogenous capital formation is crucial. In a static model, residence-based (savings) taxes are lump-sum taxes. In a two-period model, the tax externalities are very different from those in a fully dynamic model, as we emphasized in Gross et al. (2017) in a context where only source-based taxes can be used. This difference may be even more pronounced when residence-based taxes are also available because of their effect on the rates of return to savings, thereby on capital accumulation, and hence the

\footnotetext{
${ }^{1}$ See European Union (2011), OECD (2017), and OECD (2018).
} 
global supply of capital over time. We restrict our attention to the case of perfect commitment, in order to establish a benchmark.

We prove analytically that, at any interior steady state, all capital taxes are zero. This result is quite important for our study: When countries have the same subjective discount factor, a non-degenerate steady state only exists if residence-based capital taxes are identical across countries-otherwise the country with the highest aftertax rate of return will, in the limit, own the entire global stock of wealth. Therefore, if countries were to differ in endowments, technology, or their agents' preferences, and if these differences were to result in different choices of residence-based capital taxes, then the world economy would not converge to a non-degenerate wealth distribution. However, because we show that all countries choose the same long-run residence-based capital tax rate (zero) regardless of asymmetries, we can sensibly study environments where countries differ in more or less arbitrary ways, provided only that they have the same subjective discount factor.

Our next finding in this new setting is that, when countries are symmetric or differ with respect to population size and/or productivity only, the equilibrium of a noncooperative game is identical to the equilibrium in the absence of capital mobility; in other words, it is as if the two economies were closed. We prove this analytically (in an n-country world) and verify it numerically (in a two-country world). In such an environment, source-based capital income taxes are always zero. The result that source-based capital income taxes are always zero is similar to those by Bucovetsky and Wilson (1991) and Eggert and Haufler (1999), who focus on identical countries, and can thus be seen as an extension of these results from a two-period to an infinitehorizon setting. In our fully dynamic model, however, residence-based capital taxes are only initially high and then go to zero, as in a closed economy.

In consonance with this surprising result, we show that the fiscal externalities associated with source-based capital taxes vanish when residence-based capital income taxes are allowed. This holds even when countries differ with respect to other features than population and productivity. 
However, while the fiscal externalities always vanish, when jurisdictions differ with respect to some fundamentals not related to size or productivity, such as the initial asset position, source-based taxes are associated with a terms-of-trade externality, which does not arise for residence-based taxes. This externality, however, is tiny compared to its counterpart when source-based taxes are the only type of capital tax allowed. Importantly, while there are significant welfare costs of capital mobility when only source-based taxes are allowed, we observe small, but positive, welfare gains from capital mobility once savings taxes are available. The reason is that tax competition is no longer harmful, and there are potential gains from (intertemporal) trade. Therefore, increased capital-market integration may not be as problematic as many have feared.

The rest of the paper is organized as follows. Section 2 discusses some of the related literature. Section 4 presents the model framework and defines our equilibrium concept. Section 4.2 contains our analytical results regarding optimal policy and discusses the externalities stemming from capital taxes. In Section 5 we show our quantitative results. Section 6 concludes.

\section{Related literature}

A large literature exists on tax competition with source-based taxes when the capital stock is exogenously given. The main idea is captured in the seminal papers by Zodrow and Mieszkowski (1986) and Wilson (1986): when capital becomes internationally mobile, then countries will lower their capital tax rates and provide less public goods; this is inefficient and all countries would gain by a coordinated tax increase. There is not enough space here to do justice to the many contributions that followed, so we refer here to three excellent summaries/surveys. Wilson and Wildasin (2004) review the theoretical arguments about whether tax competition is

a "bane or boon" by taking into account that tax competition may benefit citizens if, for example, the government is non-benevolent as in Edwards and Keen (1996) 
and Eggert (2001). Nicodème (2006) situates the policy debate in the context of the theoretical literature. Zodrow (2010) focusses on the nexus of the empirical and theoretical literature, noting that capital mobility has increased over time and is high, that tax competition has taken place over statutory rates, but that the broadening of the tax base has led to relatively constant effective marginal tax rates. One main implication from the literature is that increased capital mobility will lead to an overall decrease in tax rates. Exceptions include Cai and Treisman (2005) with productive government spending and Baldwin and Krugman (2004) with trade by monopolistically competitive firms. In these models, some countries lower their capital taxes in response to tax competition while others increase theirs.

The various externalities associated with tax competition under the source principle and an exogenous capital stock are well understood. The main one, which dominates the tax competition literature, is the fiscal externality: a higher capital tax rate in one jurisdiction leads to an outflow of capital to other jurisdictions, and thus a higher tax base in them. If governments set capital taxes non-cooperatively, then they do not take into account how their actions affect others' tax bases. Because of this positive externality, capital taxes in an open economy would tend to be lower than in a closed economy.

Some more recent theoretical work argues that capital market integration might, in some circumstances, lead to overtaxation of capital at the source. This literature emphasizes the presence of alternative externalities that could counteract the aforementioned fiscal externality. ${ }^{2}$

In the context of a static model with an exogenous capital stock, allowing for residence-based capital taxes makes the optimal-tax problem trivial: these taxes are then equivalent to lump-sum taxes which are generally assumed not to be available in this type of framework (otherwise the optimal-tax problem is trivial). One way to avoid triviality is to endogenize capital in the context of a two-period model; that is

\footnotetext{
${ }^{2}$ See, for example, Keen and Kotsogiannis (2002), Kessler et al. (2002), Makris (2006), Lockwood and Makris (2006), Wooders et al. (2007), Bénassy-Quéré et al. (2007), and the works cited therein. Wilson (1999) and Wilson and Wildasin (2004) survey some of the previous literature.
} 
done in, for instance, Bucovetsky and Wilson (1991) and Eggert and Haufler (1999) with identical countries. Becker and Fuest (2011) also study a two-period model, but capital flows in their setting are in terms of mergers and acquisitions instead of foreign direct investment, in contrast to most of the literature. In this setting, the availability of residence-based taxes may actually result in higher global distortions, whereas policy with only source-based capital taxes is efficient. However, these papers do not fully take into account the dynamic aspects of taxation.

The literature on optimal taxation in a multi-period setting, pioneered by Chamley (1986) and Judd (1985), has demonstrated that the results concerning capital taxes differ markedly between a fully dynamic economy with endogenous capital accumulation and one where capital is given as an endowment. Chamley and Judd found that the optimal capital tax should initially be as high as possible (to tax the initial capital stock, which is given as an endowment in the fully dynamic model as well), but zero in the long run. Even though later work, for instance by Aiyagari (1995) or Erosa and Gervais (2002), qualified the zero-tax result, they obtained the same policy prescription: that capital accumulation should be undistorted in the long run. In a large class of models, including New Dynamic Public Finance work, ${ }^{3}$ the modified golden rule of capital holds in the long run. ${ }^{4}$ An exception to this rule is found in an environment where the tax system is incomplete (fewer tax instruments than inputs into the production function), as Correia (1996b) and subsequent studies have shown. All these papers assume perfect commitment. Since Kydland and Prescott (1977) it is well known that capital taxes are too high in the absence of commitment; see also Klein and Ríos-Rull (2003) and Klein et al. (2008). While perfect commitment may not be a realistic assumption, it serves an important role as a benchmark, as Kydland and Prescott (1980) argue.

In summary, there has been a lot of work on tax competition in static or two-period models and on optimal taxation in a fully dynamic, but closed economy. Much less attention has been devoted to optimal (or equilibrium) taxation in a fully dynamic

\footnotetext{
${ }^{3}$ See Golosov et al. (2003) and Kocherlakota (2010).

${ }^{4}$ See also Gross (2015b).
} 
open economy, i.e. when capital taxes distort both the intertemporal savings margin as well as the allocation of capital across countries. A few papers employ a formally dynamic model, but make specific functional-form assumptions so that capital taxes do not affect the savings decision, as for instance in Köthenbürger and Lockwood (2010) and Arcalean (2018). Lejour and Verbon (1998) only analyze steady states without taking into account the transition. Wildasin (2003), Mendoza and Tesar (2005), Becker and Rauscher (2007), and Hatfield (2015) impose time-invariance on tax rates, meaning that the capital taxes at each time are a compromise between the desire to highly tax the initial capital stock and to not tax capital in the long run. This rules out any detailed period-by-period analysis of externalities. Klein et al. (2005) and Quadrini (2005) study equilibrium taxation in an open economy with limited commitment. Quadrini (2005) shows that in this context, tax competition does reduce capital taxes, but that this constitutes a welfare improvement.

If lack of commitment implies inefficiently high capital taxes, and tax competition drives down capital taxes, then it is important to know what the solution with perfect commitment is. It creates, as mentioned before, a benchmark against which other policies can be evaluated. Under the assumption of perfect commitment, Correia (1996a) and Angyridis (2007) analyze optimal taxation in fully dynamic small open economies where the international rate of return is exogenously given; these economies have the property that, after exactly one period, the economy converges to the long-run steady state where capital taxes are zero. ${ }^{5}$

Gross (2014) provides a framework to analyze optimal taxation in large open dynamic economies and finds that capital taxes are zero in the long run; Gross (2015a) extends these results to a larger class of models and Gross (2018) examines the effects

\footnotetext{
${ }^{5}$ Correia (1996a, p.698) also discusses the similarity of the small open-economy solution (with residence-based taxes) to the closed-economy solution. However, in her model there is no transitional period with a capital tax strictly between 0 and 100 percent. This is because the rest of the world is assumed to be in steady state. In our model, which includes the case of a small open economy as a limiting case, all governments choose their taxes optimally at the same time, which leads to identical solutions in every period for a closed and open economy, provided that countries are sufficiently symmetric; specifically, if they differ, if at all, only with respect to population size and/or productivity.
} 
of intergovernmental transfers in this context. These three papers all focus entirely on the long run and do not analyze the transition to it.

Gross et al. (2017) study the entire transition from an arbitrary starting point to a steady state. That work involved decomposing, analytically and computationally, the externalities stemming from source-based capital taxes when residence-based taxes are not available. Notably, in that paper, we found a savings externality (which is obviously not present in static models), whereby governments do not take into account that higher taxes will reduce savings and thus the capital stock, and thereby harm other countries. This externality is zero at first, but then grows over time and in the long run completely offsets the other externalities. The present study does for a setting with both residence-based and source-based capital taxes what Gross et al. (2017) did for a setting with source-based capital taxes alone.

\section{The closed and the small open economy}

In this section, we lay out the model environment and derive an equivalence result for a closed economy and identical small open economies. In the next section (Section 4), we generalize the result and analyze economies of any size and number and various types of asymmetry.

Each country has a representative consumer and a representative competitive firm. Physical capital is costlessly and immediately mobile across borders, while labour is immobile. Savings are allocated across capital and government bonds in the various jurisdictions by transnational, competitive investors whose behaviour guarantees that after-tax rates of return to all assets are equalized. The government of each country aims to maximize its own representative consumer's utility, issues government bonds and can levy capital and labour taxes to finance a stream of endogenous expenditures.

Capital taxes take the form of source-based taxes, which are paid by firms in the 
country where they produce, and residence-based taxes, which are paid by households in the country where they live. Residence-based taxes are paid on capital income net of source-based taxes. The governments are able to commit to their future taxes and thus engage in a one-shot game with each other, announcing a sequence of taxes and bond issues at time zero, to which consumers, investors and firms then react.

Since we only consider closed and small open economies in this section, there is no strategic interaction between governments. Therefore, we do not treat the optimal taxation problem as a game between governments.

\subsection{The Representative Consumer}

Let there be a measure $\chi^{i}$ of consumers in each country $i$. A representative consumer in a country $i$ takes prices and taxes as given and ranks allocations according to the following lifetime utility function.

$$
\sum_{t=0}^{\infty} \beta^{t}\left[u\left(c_{t}^{i}, l_{t}^{i}\right)+v\left(g_{t}^{i}\right)\right]
$$

where $u(c, l)$ is a period utility function that is strictly increasing and concave in consumption $c$ and leisure $l$. The subjective discount factor is denoted by $\beta \in(0,1)$. Government spending is denoted by $g_{t}^{i}$ and $v(\cdot)$ is a strictly increasing and concave function, with $\lim _{g \rightarrow 0} v_{g}=\infty$. The consumer divides up her total available time between labour $n_{t}^{i}$ and leisure $l_{t}^{i}=1-n_{t}^{i}$. The per-period budget constraint is:

$$
c_{t}^{i}=\left(1-\tau_{n, t}^{i}\right) w_{t}^{i} n_{t}^{i}+\left[1+R_{t}\left(1-\tau_{a, t}^{i}\right)\right] a_{t}^{i}-a_{t+1}^{i} .
$$

where $w_{t}^{i}$ is the wage, $\tau_{a, t}^{i}$ the tax on savings, $\tau_{n, t}^{i}$ the tax on labour, $a_{t}^{i}$ are asset holdings, and $R_{t}$ is the world market rate of return. In an open-economy context, $\tau_{\mathrm{a}, \mathrm{t}}^{\mathrm{i}}$ should be thought of as a residence-based tax on capital income; the notation is motivated by the fact that it is a tax on asset returns (from whatever source). Initial asset holdings $a_{0}^{i}$ are exogenously given. 
Utility maximization with respect to labour supply $n_{t}^{i}$ and private consumption $c_{t}^{i}$ implies the familiar labour-leisure trade-off and "Euler" equation characterizing the optimal trade-off between consumption in the current period versus the next (subscripts denote partial derivatives, e.g. $\left.u_{c, t}^{i}=\partial u\left(c_{t}^{i}, n_{t}^{i}\right) / \partial c_{t}^{i}\right)$ :

$$
\begin{aligned}
& u_{l, t}^{i}=u_{c, t}^{i}\left(1-\tau_{n, t}^{i}\right) w_{t}^{i} \\
& u_{c, t}^{i}=\beta u_{c, t+1}^{i}\left[1+R_{t+1}\left(1-\tau_{a, t+1}^{i}\right)\right]
\end{aligned}
$$

Equations (2), (3), and (4), together with initial asset holdings and no-Ponzi-scheme conditions (which we leave out to avoid tedious notation) characterize consumer behaviour.

\subsection{Firms and Production}

There are many identical firms which are perfectly competitive. They rent capital $k_{t}^{i}$ and hire labour $n_{t}^{i}$ to produce output according to a concave production function with constant returns to scale, $y_{t}^{i}=F\left(k_{t}^{i}, n_{t}^{i}\right)=f\left(k_{t}^{i}, Z^{i} n_{t}^{i}\right)-\delta k_{t}^{i}$. The production function includes a linear depreciation term, where the depreciation rate is denoted by $\delta . Z$ is labour productivity. The variables $n_{t}^{i}, k_{t}^{i}$ and $y_{t}^{i}$ are all in per capita terms, so that $y_{t}^{i}$, for instance, is output per head. Our assumptions imply zero profits and the standard conditions regarding the relationship between input prices and marginal products:

$$
\begin{aligned}
w_{t}^{i} & =F_{n, t}^{i} \\
r_{t}^{i} & =F_{k, t}^{i} .
\end{aligned}
$$

We assume throughout that the marginal product of capital is strictly positive, and hence $r_{t}^{i}>0$. 


\subsection{Investors}

Investors collect savings on behalf of consumers and invest them in capital $k_{t}^{i}$ and government bonds $b_{t}^{i}$ in such a way as to maximize their profits (which are zero in equilibrium due to perfect competition and constant returns to scale). ${ }^{6}$ Capital returns are taxed at source in each country at rate $\tau_{\mathrm{k}, \mathrm{t}}^{\mathrm{i}}$. Let $\widehat{r}_{\mathrm{t}}^{\mathrm{i}}$ denote the net return on government bonds. ${ }^{7}$ The representative investor's profit maximization problem in each period is

$$
\begin{gathered}
\max _{\left\{k_{t}^{i}, b_{t}^{i}, a_{t}^{i}\right\}_{i=1}^{m}} \sum_{i} \chi^{i}\left(r_{t}^{i}\left(1-\tau_{k, t}^{i}\right) k_{t}^{i}+\hat{r}_{t}^{i} b_{t}^{i}-a_{t}^{i} R_{t}\right) \\
\text { s.t. } \sum_{i} \chi^{i} a_{t}^{i}=\sum_{i} \chi^{i}\left(k_{t}^{i}+b_{t}^{i}\right) .
\end{gathered}
$$

The first-order conditions imply the usual no-arbitrage conditions. Specifically, the net returns on each asset have to be equal to each other and the international rate of return:

$$
R_{t}=r_{t}^{i}\left(1-\tau_{k, t}^{i}\right)=\widehat{r}_{t}^{i} .
$$

Due to our assumption of perfect and immediate capital mobility, these no-arbitrage conditions hold in every period $t$, including at $t=0$. Equations (8) and (9) characterize the investors' behaviour. Anticipating the analysis of Section 4 we note that,

\footnotetext{
${ }^{6}$ Investors are not a necessary element of our model, but they simplify the exposition and analysis. In the absence of investors, all consumers would have to choose the composition of their investment portfolio, and not just its total value. This means that for each country, the representative consumer there would have to choose how much capital to invest in each of the countries (and similarly for government bonds). The number of variables would thus explode as the number of countries gets larger. Though this does not noticeably affect the analysis of a small open economy, it becomes important in the context of Section 4, where we assume that there are $m$ different (large) countries. In our setup, we have government bonds, capital and private assets in each country, or $3 \mathrm{~m}$ financial variables; without investors, the number of such variables would be $2 \mathrm{~m}^{2}$. Furthermore, the aggregate capital stock employed in each country and the net foreign asset position in each country are uniquely determined, but not what fraction of a given country's capital stock is owned by residents of another; without investors, the portfolio composition of each consumer would thus be indeterminate. See also Gross (2014).

${ }^{7}$ The absence of arbitrage opportunities requires that returns on government bonds have to be equal to returns on capital; see below. It therefore does not matter whether bond returns are taxed at source or not at all.
} 
in the context of large open economies, imposing Equations (8) and (9), allows us to treat $\widehat{r}_{t}^{i}$ for all $i$ and $R_{t}$ as being under the control of each government $j$.

\subsection{The Government}

Each benevolent (but nationalistic) government maximizes the utility of its own representative consumer. It finances its endogenously chosen government purchases $\left\{g_{\mathfrak{t}}^{i}\right\}_{t=0}^{i \infty}$ via source- and residence-based taxes on capital income, as well as labour income taxes. Governments may also issue one-period debt (subject to a no-Ponzischeme condition, which we omit here). Initial government debt $b_{0}^{i}$ is exogenously given. In order to avoid confiscatory lump-sum taxation of initial assets, we stipulate that residential capital taxes may not exceed $100 \%$, as is common in the optimaltaxation literature. As mentioned above, residence-based capital taxes are applied to the rate of return net of source-based capital taxes. The government's per-period budget constraint can be written as

$$
g_{t}^{i}+b_{t}^{i}\left(1+R_{t}\right)=\tau_{k, t}^{i} r_{t}^{i} k_{t}^{i}+\tau_{a, t}^{i} R_{t} a_{t}^{i}+\tau_{n, t}^{i} w_{t}^{i} n_{t}^{i}+b_{t+1}^{i} .
$$

\subsection{Optimal taxation in a closed economy}

In the context of a closed economy, it is meaningless to distinguish between a sourceand a residence-based capital income tax, and so we set $\tau_{k, t}^{i}=0$. In this section, we make use of the primal approach to optimal taxation, as described in Lucas and Stokey (1983); a powerful tool in the context of a closed or small open economy. It exploits the result that an allocation forms part of a competitive equilibrium, for some prices and taxes, if and only if it satisfies (a) the sequence of resource constraints and (b) the following implementability condition (IC):

$$
\sum_{t=0}^{\infty} \beta^{t}\left[u_{c, t}^{i} c_{t}^{i}-u_{l, t}^{i} n_{t}^{i}\right]=u_{c, 0}^{i}\left[1+r_{0}^{i}\left(1-\tau_{a, 0}^{i}\right)\right] a_{0}^{i} .
$$


Equation (11) follows from eliminating after-tax prices from a consumer's intertemporal budget constraint by using the private sector optimality conditions. Since this is standard, we do not go through the derivation in detail here.

Meanwhile, the sequence of resource constraints is

$$
c_{t}^{i}+k_{t+1}^{i}+g_{t}^{i}=F\left(k_{t}^{i}, n_{t}^{i}\right)+k_{t}^{i}
$$

for $t=0,1, \ldots$ Additionally, we impose $\tau_{a, t}^{i} \leq 1$ for $t=0,1, \ldots$, and these constraints can be rewritten as follows:

$$
\tau_{a, 0}^{i} \leq 1
$$

and

$$
u_{c, t}^{i} \geq \beta u_{c, t+1}^{i}
$$

for $t=0,1, \ldots$ Alternatively, we could analyze optimal taxation in a closed economy using the dual approach; that will be relevant later on, when we analyze large open economies. See Appendix A.

\subsection{Optimal taxation in a small open economy}

In a small open economy, the rate of return $R_{t}$ is exogenously given and the implementability condition is therefore slightly modified. It becomes

$$
\sum_{t=0}^{\infty} \beta^{t}\left[u_{c, t}^{i} c_{t}^{i}-u_{l, t}^{i} n_{t}^{i}\right]=u_{c, 0}^{i}\left[1+R_{0}\left(1-\tau_{a, 0}^{i}\right)\right] a_{0}^{i} .
$$

Meanwhile, the sequence of resource constraints is

$$
\Xi_{t+1}^{i}+c_{t}^{i}+k_{t+1}^{i}+g_{t}^{i}=F\left(k_{t}^{i}, n_{t}^{i}\right)+k_{t}^{i}+\left(1+R_{t}\right) \zeta_{t}^{i}
$$

for $t=0,1, \ldots$, where $\Xi_{t}^{i}$ is the net foreign asset position (NFAP). With open economies, it is meaningful to distinguish between a source- and a residence-based capital income tax. Notice that the source-based capital income tax $\tau_{\mathrm{k}, \mathrm{t}}^{i}$ appears 
nowhere in the implementability condition (12) nor in the above sequence of resource constraints. It only appears in the no-arbitrage condition $R_{t}=r_{t}^{i}\left(1-\tau_{k, t}^{i}\right)$.

Characterizing the solution to the government's problem, we find that the first-order condition with respect to $\tau_{\mathrm{k}, \mathrm{t}}^{\mathrm{i}}$ implies that the Lagrange multiplier associated with the above no-arbitrage condition is zero. This in turn implies that the first-order conditions for the net foreign asset position and capital reduce to $F_{k, t}^{i}=R_{t}$ for $t=0,1, \ldots$ Together with the above no-arbitrage condition and $r_{t}^{i}=F_{k, t}^{i}$, we then have that $\tau_{k, t}^{i}=0$ for all $t=0,1, \ldots$, and, in particular, that $R_{0}=r_{0}$. Therefore, the implementability condition reduces to its closed-economy counterpart.

When countries are symmetric, the net foreign asset position is zero, and so we have $\Xi_{\mathrm{t}}^{i}=0$, meaning that the national resource constraints reduce to the closedeconomy resource constraints. Hence the solution to the government's problem in a small open economy has to be exactly equal that in a closed economy. This establishes equivalence between closed and symmetric small open economies, not only in steady state, but along the transition path as well. ${ }^{8}$ Notice that allowing for residence-based taxes is essential in this context: ruling them out would destroy the equivalence to the closed economy that we demonstrate here.

\section{Large open economies}

We now describe a model environment consisting of finitely many countries $i=1,2, \ldots, m$. This raises a host of conceptual issues that arise neither in a closed economy nor in a small open economy. For one, the primal approach is no longer

\footnotetext{
${ }^{8}$ This result extends that of Correia (1996a), who shows that, in a small open economy, sourcebased capital taxes should always be zero and residence-based taxes at their upper bound in the initial period, followed immediately by zero. This is in contrast to a closed economy (to which our world consisting of many identical small open economies is equivalent), where the residence-based capital income tax is at its upper limit for several periods followed by one transitional period where it is strictly between zero and the upper bound, followed by zero. The difference between the result in Correia (1996a) and ours arises because she assumes that the the whole world is already in a steady state in the initial period.
} 
valid. The reason is that the primal approach does not allow us to distinguish properly between what is exogenously given to a government and what it can influence through its policy choices. More precisely, the idea behind the primal approach is to characterize the set of allocations that can be supported as part of a competitive equilibrium by some set of prices and taxes and then let the government choose the best allocation in that set. But that idea is not useful in the context of a world consisting of large, open economies. In that context, no single country can choose freely among all the possible competitive equilibria for the world because no single country can control the policy choices of the other countries. In a non-cooperative game, a given country asks: what allocations can be implemented given the policies of the other countries? It does not ask: what allocations can be implemented for some taxes set by me and by the other countries?

Therefore, it is inappropriate to eliminate the taxes levied by other governments from the problem of a given government by using the private sector optimality conditions of those other countries. Though it is of course possible (and valid) to eliminate the given country's taxes from its own problem, that would still leave us with the tax rates of the other countries. Thus the approach, in order to remain valid, would be only partially primal, destroying its practical advantages. This leads us to adopt the dual approach. See Appendix A for a description of the dual approach as it applies to a closed economy.

\subsection{Equilibrium}

At time $t=0$, governments simultaneously announce their policies for the infinite future. Households, firms, and investors then react to the announced policies in such a way as to maximize utility/profits. Incorporating their optimality conditions as constraints into each government's problem allows us to treat all the private sector's choice variables (both at home and abroad) as each government's own control variables. When choosing its policies, each government considers the taxes and debt 
of other governments as exogenously fixed and equal to their equilibrium levels. Meanwhile, in response to a deviation from equilibrium on the part of one government, other governments respond automatically by adjusting their government spending in each period so as to satisfy their per-period (flow) government budget constraint, leaving taxes and government debt unchanged. That is, government consumption is not thought of as an action in the game-theoretic sense. This is to ensure that the world remains in competitive equilibrium, even off the equilibrium path.

Given the automatic adjustment of government spending, we may regard the setup as a game in the sense of Nash (1950), provided that no government is allowed to set policies in such a way as to force any other government to reduce their spending below zero. Thus we may regard our equilibrium concept as a Nash equilibrium, subject to this proviso.

Alternatively, we may define equilibrium in another way that avoids this implicit restriction on strategies, and which in our particular environment turns out to have exactly the same implications as the one we just described. Under this alternative equilibrium concept, other governments do not respond automatically to deviations on the part of any government. As a result, a deviation from equilibrium on the part of one government will typically render the other governments either insolvent or overfunded as private agents (investors and consumers) respond to the deviation. It follows that the setup is not a game in the sense of Nash (1950). This is because the set of feasible strategies available to any one government depends on what the others are doing; Nash's concept of a game explicitly rules this out.

The setup then instead becomes a "generalized game" in the sense of Debreu (1952), a concept applied in the seminal work by Arrow and Debreu (1954). In the words of Dasgupta and Maskin (2015), a generalized game "allow[s] for the possibility that a player's set of strategies might depend on the strategy choices of other players." We could then apply the equilibrium concept that Debreu developed for the purpose of analyzing generalized games, namely a social equilibrium. A social equilibrium is a 
strategy profile such that each agent chooses the best strategy from the set of strategies available to her given the strategies of the other agents. Notice that each agent in a social equilibrium, when contemplating what to do, ignores the fact that her out-of-equilibrium choices may render the other agents' equilibrium strategies infeasible. ${ }^{9}$ We note here, for the record, that the social equilibrium concept in Debreu (1952) is not the same as the concept of competitive equilibrium defined in Arrow and Debreu (1954).

The social equilibrium concept implies that off-equilibrium behaviour is generically not consistent with competitive equilibrium for the world as a whole; the worldwide resource constraint will typically not hold if a single government deviates, though it will of course hold in a social equilibrium. ${ }^{10}$ As we mentioned above, this alternative equilibrium concept leads here to the same prediction in terms of equilibrium allocations and policies with that under the above equilibrium concept. ${ }^{11}$

We note also that there are many distinct specifications of the game between governments that, unlike social equilibrium, rely on an automatic adjustment of some policy. For instance, instead of letting government spending adjust automatically so as to satisfy the flow government budget constraint, labour taxes could adjust automatically. These alternative equilibrium concepts are not equivalent; not to our concept and not to each other. ${ }^{12}$

\footnotetext{
${ }^{9}$ See, for instance, Equations (4) and (5) in Dasgupta and Maskin (2015).

${ }^{10}$ A more detailed discussion of the equilibrium concept as applied in this paper can be found in Gross (2014), which considers source-based taxes.

${ }^{11}$ This equivalence result unfortunately does not generalize much; it typically fails if the utility function is not additively separable over private and public consumption. Also, the equilibrium concept that utilizes automatic adjustment of government spending can obviously not be used in an environment where government spending is exogenously fixed, and so the question of equivalence would not even arise. In the latter case, however, the social equilibrium policies (and allocations) remain well-defined.

${ }^{12}$ For a deeper examination of these equilibrium issues, when one fiscal-policy variable per period adjusts residually, see Gross (2018).
} 


\subsection{Optimal policy}

We now characterize the optimal policy of some fixed country j's government, using Lagrange's theorem. The Lagrangian is

$$
\begin{aligned}
\mathcal{L}^{j}= & \sum_{t=0}^{\infty} \beta^{t}\left\{u^{j}\left(c_{t}^{j}, l_{t}^{j}\right)+v^{j}\left(g_{t}^{j}\right)\right. \\
& +\psi_{t}^{j}\left[\tau_{k, t}^{j} r_{t}^{j} k_{t}^{j}+\tau_{a, t}^{j} R_{t} a_{t}^{j}+\tau_{n, t}^{j} w_{t}^{j} n_{t}^{j}+b_{t+1}^{j}-\left(1+R_{t}\right) b_{t}^{j}-g_{t}^{j}\right] \\
& +\sum_{i=1}^{m} \theta_{t}^{i, j}\left[\left(1-\tau_{n, t}^{i}\right) w_{t}^{i} n_{t}^{i}+\left[1+R_{t}\left(1-\tau_{a, t}^{i}\right)\right] a_{t}^{i}-a_{t+1}^{i}-c_{t}^{i}\right] \\
& +\sum_{i=1}^{m} \mu_{t}^{i, j}\left[\left(1-\tau_{n, t}^{i}\right) w_{t}^{i} u_{c, t}^{i}-u_{l, t}^{i}\right] \\
& +\sum_{i=1}^{m} \tau_{t}^{i, j}\left\{\beta u_{c, t+1}^{i}\left[1+R_{t+1}\left(1-\tau_{a, t+1}^{i}\right)\right]-u_{c, t}^{i}\right\} \\
& +\sum_{i=1}^{m} \gamma_{t}^{i, j}\left[r_{t}^{i}\left(1-\tau_{k, t}^{i}\right)-R_{t}\right] \\
& +\omega_{t}^{j} \sum_{i=1}^{m} \chi^{i}\left(a_{t}^{i}-k_{t}^{i}-b_{t}^{i}\right) \\
& \left.+\phi_{t}^{j} R_{t}\left(1-\tau_{a, t}^{j}\right)\right\},
\end{aligned}
$$

where, for instance, $\theta_{t}^{i, j}$ is the Lagrange multiplier associated with country $j^{\prime}$ 's government optimization problem and the household budget constraint of residents of country $i$. Note that $w_{t}^{i}$ and $r_{t}^{i}$ are functions of $k_{t}^{i}$ and $n_{t}^{i}$ as described in Equations (5) and (6), and $l_{\mathrm{t}}^{\mathrm{i}}=1-\mathrm{n}_{\mathrm{t}}^{\mathrm{i}}$. The constraint associated with the multiplier $\phi_{\mathrm{t}}^{j}$ states that the after-tax returns on assets cannot be negative.

In what follows, we will never have occasion to explicitly refer to the Lagrange multipliers associated with the optimization problem of more than one country at a time. We will therefore suppress the second superscript $j$ in $\theta_{t}^{i, j}, \mu_{t}^{i, j}, \zeta_{t}^{i, j}$ and $\gamma_{t}^{i, j}$, and write simply $\theta_{\mathrm{t}}^{\mathrm{i}}, \mu_{\mathrm{t}}^{\mathrm{i}}, \zeta_{\mathrm{t}}^{\mathrm{i}}$ and $\gamma_{\mathrm{t}}^{\mathrm{i}}$, where the single superscript $i$ refers to a particular constraint rather than a particular country's optimization problem. Similarly we shall write $\psi_{\mathrm{t}}, \omega_{\mathrm{t}}$ and $\phi_{\mathrm{t}}$ rather than $\psi_{\mathrm{t}}^{\mathrm{j}}, \omega_{\mathrm{t}}^{\mathrm{j}}$ and $\phi_{\mathrm{t}}^{\mathrm{j}}$. 
We have substituted in for the equilibrium prices of governments bonds, i.e. replaced $\hat{r}_{t}^{j}$ with $R_{t}$, thus eliminating the corresponding investors' optimality conditions from the problem. The set of control variables for country $j$ 's government is

$$
X=\left\{\left\{c_{t}^{i}, n_{t}^{i}, k_{t}^{i}, a_{t+1}^{i}\right\}_{i=1}^{m}, g_{t}^{j}, b_{t+1}^{j}, \tau_{a, t}^{j}, \tau_{k, t}^{j}, \tau_{n, t}^{j}, R_{t}\right\}_{t=0}^{\infty} .
$$

\subsection{Intertemporal Efficiency}

In this section, we show that if a country converges to a strictly positive stationary allocation $\left(c^{j}>0, n^{j}>0, g^{j}>0\right)$ or "steady state", then its government wants to set taxes so as to ensure that this allocation is intertemporally efficient. What we mean by that is that it satisfies the modified golden rule:

Definition 1 A stationary allocation for a given country $j$ is called intertemporally efficient if it satisfies

$$
\beta\left[1+\mathrm{F}_{k, t}^{j}\right]=1 .
$$

In our context, given our choice of tax instruments, intertemporal efficiency implies that $\left(1-\tau_{k, t}^{j}\right)\left(1-\tau_{a, t}^{j}\right)=1$.

In more detail:

Proposition 1 If an economy converges to an interior stationary allocation, then its government wants to set taxes so as to ensure that this allocation is intertemporally efficient. 
Proof. The following first-order conditions are relevant for the proof:

$$
\begin{aligned}
& k_{t}^{j}: \psi_{t} \tau_{k, t}^{j} r_{t}^{j}+\left(\psi_{t} \tau_{n, t}^{j} n_{t}^{j}+\theta_{t}^{j} n_{t}^{j}\left(1-\tau_{n, t}^{j}\right)+\mu_{t}^{j} u_{c, t}^{j}\left(1-\tau_{n, t}^{j}\right)\right) \frac{\partial w_{t}^{j}}{\partial k_{t}^{j}} \\
& \quad+\left(\psi_{t} \tau_{k, t}^{j} k_{t}^{j}+\gamma_{t}^{j}\left(1-\tau_{k, t}^{j}\right)\right) \frac{\partial r_{t}^{j}}{\partial k_{t}^{j}}=\chi^{j} \omega_{t} \\
& g_{t}^{j}: v_{g, t}^{j}=\psi_{t} \\
& b_{t+1}^{j}: \psi_{t} / \beta-\left(1+R_{t+1}\right) \psi_{t+1}=\chi^{j} \omega_{t+1} \\
& \tau_{n, t}^{j}: \psi_{t} w_{t}^{j} n_{t}^{j}=\mu_{t}^{j} u_{c, t}^{j} w_{t}^{j}+\theta_{t}^{j} n_{t}^{j} w_{t}^{j} \\
& \tau_{k, t}^{j}: \psi_{t} r_{t}^{j} k_{t}^{j}=\gamma_{t}^{j} t_{t}^{j} .
\end{aligned}
$$

Combining Equation (15) with Equations (18) and (19) yields

$$
\chi^{j} \omega_{t}=\psi_{t} \tau_{k, t}^{j} r_{t}^{j}+\psi_{t} n_{t}^{j} \frac{\partial w_{t}^{j}}{\partial k_{t}^{j}}+\psi_{t} k_{t}^{j} \frac{\partial r_{t}^{j}}{\partial k_{t}^{j}} .
$$

From constant returns to scale we have the identity that $\mathrm{F}(\mathrm{k}, \mathrm{n}) \equiv w \mathrm{n}+\mathrm{rk}$ (where of course $w$ and $r$ are the marginal products of labour and capital, respectively), so that $n_{t}^{j} \cdot \partial w_{t}^{j} / \partial k_{t}^{j}=-k_{t}^{j} \cdot \partial r_{t}^{j} / \partial k_{t}^{j}$ and therefore

$$
\chi^{j} \omega_{t}=\psi_{t}^{j} \tau_{k, t}^{j} r_{t}^{j} .
$$

If the economy converges to a stationary allocation, where $g_{t+1}^{j}=g_{t}^{j}>0$, it follows that $\psi_{\mathrm{t}}=\psi_{\mathrm{t}+1}$ from (16). ${ }^{13}$ Moreover, because the stationary allocation also satisfies $c_{t+1}^{j}=c_{t}^{j}$ and $n_{t+1}^{j}=n_{t}^{j}$, we can conclude from the household's Euler equation (4) and the no-arbitrage condition (9) that

$$
1+r_{t}^{j}\left(1-\tau_{a, t}^{j}\right)\left(1-\tau_{k, t}^{j}\right)=1 / \beta \text {. }
$$

Combining this with equation (17), we have

$$
\chi^{j} \omega_{t}=-\psi_{t}^{j} \tau_{a, t}^{j}\left(1-\tau_{k, t}^{j}\right) r_{t}^{j} .
$$

\footnotetext{
${ }^{13}$ To put this in the context of Straub and Werning (2020), we do not assume that Lagrange multipliers converge. However, our result does depend on the assumption that the economy converges to an interior (non-degenerate) steady state. The contrary possibility, while genuine, is a remote one. It arises only if initial government debt is extremely high and the intertemporal elasticity of substitution is strictly below unity.
} 
Equations (21) and (23) imply that $\left(1-\tau_{\mathrm{a}, \mathrm{t}}^{\mathrm{j}}\right)\left(1-\tau_{\mathrm{k}, \mathrm{t}}^{\mathrm{j}}\right)=1$. From equation (22), we can thus infer that with a stationary allocation, $1+\mathrm{F}_{\mathrm{k}, \mathrm{t}}^{\mathrm{j}}=1 / \beta$.

Combining intertemporal efficiency with the no-arbitrage condition that must hold under capital mobility, it follows that $\tau_{a, t}^{i}=\tau_{a, t}^{j}$ for all $i$ and $j$ so that all countries prefer to tax assets at the same rate in a non-degenerate steady state.

This result is interesting in itself, but it is also crucial for the existence of a nondegenerate steady state for the world as a whole, i.e. one where all countries converge to non-zero levels of private and public consumption. It defuses the following challenge to any open-economy model where taxes are endogenous: We know that if each country has the same subjective discount factor and capital can be traded across countries, then all countries must have the same after-tax rates of return; otherwise, the country or countries with the highest one will own all capital in the long run. With capital mobility, equal after-tax rates of return implies equal residence-based capital tax rates. But why a priory would asymmetric countries choose the same residence-based tax rates? Fortunately, the aforementioned result implies equal residence-based capital income taxes across countries. Thus we can safely conclude that, for a large set of parameter values, including those where countries differ significantly in many dimensions, there is a non-degenerate steady state for the world, provided only that the subjective time discount factor $\beta$ is identical across countries.

\subsection{Zero Capital Taxes}

Chamley (1986) found that optimal capital taxes are zero in the long-run in a closed economy, for the specific model also considered here. Gross (2014) showed that the Chamley result extends to open economies (with only source-based capital taxes). In this section, we prove that if Lagrange multipliers converge, then both residenceand source-based capital taxes are zero in the long run. ${ }^{14}$ In our numerical exper-

\footnotetext{
${ }^{14}$ All results hold whether government spending is endogenous or exogenous (as long as the eco-
} 
iments, we have not come across any indications that Lagrange multipliers would not converge. Furthermore, it can be shown that if allocations converge and the growth rates of taxes or Lagrange multipliers converge, then the limiting growth rates are zero; in other words, taxes and Lagrange multipliers then do in fact converge.

Proposition 2 If all economies converge to an interior stationary allocation and Lagrange multipliers converge, then both source-and residence-based capital taxes converge to zero.

Proof. The following additional first-order conditions are relevant for the proof:

$$
\begin{aligned}
& a_{t+1}^{j}: \psi_{t+1} \tau_{a, t+1}^{j} R_{t+1}+\theta_{t+1}^{j}\left[1+R_{t+1}\left(1-\tau_{a, t+1}^{j}\right)\right]-\theta_{t}^{j} / \beta=-\chi^{j} \omega_{t+1} \\
& a_{t+1}^{i, i \neq j}: \theta_{t+1}^{i}\left[1+R_{t+1}\left(1-\tau_{a, t+1}^{i}\right)\right]-\theta_{t}^{i} / \beta=-\chi^{i} \omega_{t+1} .
\end{aligned}
$$

From the Euler equation (4) of household $i \neq j$, we have $1 / \beta=1+R_{t+1}\left(1-\tau_{a, t+1}^{i}\right)$, which together with Equation (25) implies $\omega=0$. Doing the same for the households in country $j$ and using $\omega=0$ shows that $\psi \tau_{a, t}^{j} R_{t}=0$; since $\psi>0$ and $R_{t}>0$, it follows that $\tau_{a, t}^{j}=0$. As shown before, $1+r_{t}^{j}\left(1-\tau_{a, t}^{j}\right)\left(1-\tau_{k, t}^{j}\right)=1 / \beta$ and $1+r_{t}^{j}=1 / \beta$, so $\tau_{k, t}^{j}=0$.

\subsection{Equivalence of Closed and Open Economies}

Our most surprising result is that if countries are symmetric, except possibly in terms of population size and/or labour productivity, then the solution to each government's optimization problem is identical in all periods for a closed and an open economy. The main idea of the proof is to establish that, if there is sufficient symmetry across jurisdictions, the additional constraints implied by international capital mobility (no-arbitrage conditions and world capital market clearing) are nonbinding in the sense that the associated Lagrange multipliers vanish.

nomy converges to an interior steady state). Including transfer payments from governments to citizens does not affect this result either (although the transition certainly looks different). 
Proposition 3 If all economies differ only, if at all, in country size $\chi^{i}$ and/or labour productivity $Z^{i}$, and if initial assets $\mathrm{a}_{0}^{i} / Z^{i}$ and debt $\mathrm{b}_{0}^{i} / Z^{i}$ per efficiency unit of labour are common across countries, then the open-economy solution is identical to the closed-economy solution.

Proof. We reformulate the problem slightly, by eliminating $R_{t}$ as a choice variable and replacing it with the after-tax return $r_{t}^{i}\left(1-\tau_{k, t}^{i}\right)$; this obviously removes one constraint, now there are only $m-1$ constraints related to the no-arbitrage condition. We also define $\tilde{r}_{t}^{i} \equiv r_{t}^{i}\left(1-\tau_{k, t}^{i}\right)$ and use $\tilde{r}_{t}^{j}$ as a choice variable instead of $\tau_{k, t}^{j}$. This is possible because $\tau_{k, t}^{j}$ is always multiplied by $r_{t}^{j}$ in the problem above. $\tilde{r}_{t}^{i}$, for $i \neq j$, is not a choice variable, since the foreign taxes are not choice variables. The newly formulated problem is then

$$
\begin{aligned}
\mathcal{L}= & \sum_{t=0}^{\infty} \beta^{t}\left\{u^{j}\left(c_{t}^{j}, l_{t}^{j}\right)+v^{j}\left(g_{t}^{j}\right)\right. \\
& +\psi_{t}\left[r_{t}^{j} k_{t}^{j}-\tilde{r}_{t}^{j} k_{t}^{j}+\tau_{a, t}^{j} \tilde{r}_{t}^{j} a_{t}^{j}+\tau_{n, t}^{j} w_{t}^{j} n_{t}^{j}+b_{t+1}^{j}-\left(1+\tilde{r}_{t}^{j}\right) b_{t}^{j}-g_{t}^{j}\right] \\
& +\sum_{i=1}^{m} \theta_{t}^{i}\left[\left(1-\tau_{n, t}^{i}\right) w_{t}^{i} n_{t}^{i}+\left[1+\tilde{r}_{t}^{i}\left(1-\tau_{a, t}^{i}\right)\right] a_{t}^{i}-a_{t+1}^{i}-c_{t}^{i}\right] \\
& +\sum_{i=1}^{m} \mu_{t}^{i}\left[\left(1-\tau_{n, t}^{i}\right) w_{t}^{i} u_{c, t}^{i}-u_{l, t}^{i}\right] \\
& +\sum_{i=1}^{m} \zeta_{t}^{i}\left\{\beta u_{c, t+1}^{i}\left[1+\tilde{r}_{t+1}^{i}\left(1-\tau_{a, t+1}^{i}\right)\right]-u_{c, t}^{i}\right\} \\
& +\sum_{i \neq j} \gamma_{t}^{i}\left[\tilde{r}_{t}^{j}-\tilde{r}_{t}^{i}\right] \\
& +\omega_{t} \sum_{i=1}^{m} \chi^{i}\left(a_{t}^{i}-k_{t}^{i}-b_{t}^{i}\right) \\
& \left.+\phi_{t} \tilde{r}_{t}^{j}\left(1-\tau_{a, t}^{j}\right)\right\}
\end{aligned}
$$

with the following set of choice variables

$$
\tilde{X}=\left\{\left\{c_{t}^{i}, n_{t}^{i}, k_{t}^{i}, a_{t+1}^{i}\right\}_{i=1}^{m}, g_{t}^{j}, b_{t+1}^{j}, \tau_{a, t}^{j}, \tilde{r}_{t}^{j}, \tau_{n, t}^{j}\right\}_{t=0}^{\infty}
$$

where $\tilde{r}_{t}^{i}:=r_{t}^{i}\left(k_{t}^{i}, n_{t}^{i}\right)\left(1-\tau_{k, t}^{i}\right)$. 
The difference between an open and a closed economy is that in an open economy the capital-market clearing condition (with multiplier $\omega_{t}$ ) does not necessarily imply that $a_{t}^{j}=k_{t}^{j}+b_{t}^{j}$ and that there are the additional no-arbitrage conditions (with multipliers $\left.\gamma_{t}^{i}, i \neq j\right)$. The other countries' household optimality conditions and budget constraints (with multipliers $\theta_{t}^{i}, \mu_{t}^{i}, \zeta_{t}^{i}, i \neq j$ ) are not directly affected by domestic choice variables. Therefore, if we can show that the capital-market clearing condition in an open economy satisfies $a_{t}^{j}=k_{t}^{j}+b_{t}^{j}$ in equilibrium and that the no-arbitrage conditions are non-binding, i.e. the Lagrange multipliers $\gamma_{t}^{i}, i \neq j$ are equal to zero, then the closed and open economy solutions have to be identical. The domestic government's first-order conditions with respect to foreign private decisions will then only determine the domestic government's multipliers attached to foreign households' optimality conditions and budget constraints.

When countries are symmetric, then the open-economy capital-market clearing condition implies $a_{t}^{j}=k_{t}^{j}+b_{t}^{j}$. Note that since the constraints and variables are defined in per-capita terms, this also applies to countries which are asymmetric only in population size; moreover, due to constant returns to scale, this extends to differences in TFP. The first-order condition with respect to $\tilde{r}_{t}^{j}$ is

$$
-\psi_{t} k_{t}^{j}+\psi_{t} a_{t}^{j} \tau_{a, t}^{j}-\psi_{t} b_{t}^{j}+\theta_{t}^{j} a_{t}^{j}\left(1-\tau_{a, t}^{j}\right)+\zeta_{t-1}^{j} u_{c, t}^{j}\left(1-\tau_{a, t}^{j}\right)+\sum_{i \neq j} \gamma_{t}^{i}+\phi\left(1-\tau_{a, t}^{j}\right)=0,
$$

where $\zeta_{-1}^{j} \equiv 0$. From this condition it generally does not follow that $\gamma_{t}^{i}=0$. This is reassuring, as open and closed economies are not identical when only source-based taxes are available. The first-order condition with respect to $\tau_{a, t}^{j}$ is

$$
\psi_{t} a_{t}^{j} \tilde{r}_{t}^{j}-\theta_{t}^{j} a_{t}^{j} \tilde{r}_{t}^{j}-\zeta_{t-1}^{j} u_{c, t}^{j} \tilde{r}_{t}^{j}-\phi \tilde{r}_{t}^{j}=0
$$

In an open economy, $\tilde{r}_{t}^{j}$ will optimally never be zero (otherwise it would lead to a 
complete exodus of capital), ${ }^{15}$ so we can conclude from equation (29) that

$$
\psi_{t} a_{t}^{j}\left(1-\tau_{a, t}^{j}\right)-\theta_{t}^{j} a_{t}^{j}\left(1-\tau_{a, t}^{j}\right)=\zeta_{t-1}^{j} u_{c, t}^{j}\left(1-\tau_{a, t}^{j}\right)+\phi\left(1-\tau_{a, t}^{j}\right) .
$$

Inserting this into equation (28) yields

$$
\sum_{i \neq j} \gamma_{t}^{i}=\psi_{t}\left(k_{t}+b_{t}-a_{t}\right)
$$

Since countries are symmetric, $\gamma_{\mathfrak{t}}^{i}=0$, for all $i \neq j .{ }^{16}$ It follows that the open and closed economy solutions are identical, if residence-based taxes are available. ${ }^{17}$

This result also illustrates that source-based capital taxes are only used to manipulate the terms of trade, depending on whether the country is a capital importer $\left(k_{t}+b_{t}>a_{t}\right)$ or a capital exporter $\left(k_{t}+b_{t}<a_{t}\right)$. We explore this further in the next section.

Discussion We now turn to a discussion of the intuition behind our equivalence result. To set the stage, notice that each government would ideally like to tax the exogenously given endowments. In a dynamic economy such as ours, the endowments are (i) the representative consumer's efficiency units of labour in each period and (ii) initial assets. Labour taxes, though they are distortive because leisure is endogenous, are the nearest available instrument for taxing efficiency units of labour, and so labour taxes are used in all periods under a very wide range of assumptions. Now notice that a residence-based capital tax in the initial period is literally a lumpsum tax on the endowment of initial assets, in contrast to a source-based tax, which

\footnotetext{
${ }^{15}$ Under our assumption that the marginal product of capital is positive, i.e. $r_{t}^{i}>0 \forall i$, the possibility that $\tilde{r}_{t}^{i}=0 \forall i$ would imply that $\tau_{k, t}^{i}=1 \forall i$. This cannot be an equilibrium, as an infinitesimal decrease in the source-based capital tax $\tau_{k, t}^{j}$ would lead to a non-continuous jump of the capital stock (in fact, all the capital would move into country $j$ ).

${ }^{16}$ Since the constraints and endowments for all foreign countries are identical, the Lagrange multipliers must be identical, $\gamma_{i}=\gamma_{\iota}$, for $\iota, i \neq j$, otherwise the first-order conditions with respect to variables $k_{t}^{i}$ and $n_{t}^{i}$ could not be met at the same time as those for $k_{t}^{l}$ and $n_{t}^{i}$. Because variables are defined in per-capita terms, and can be defined in terms of efficiency units of labour, this is true for differences in country size or labour productivity, too. For different country sizes, for example, the Lagrange multipliers of foreign constraints would then simply be multiplied by $\chi^{i}$.

${ }^{17}$ See Appendix A for a description of the dual approach to the optimal taxation problem of a closed economy.
} 
is not. More generally, asset income (residence-based) and capital income (sourcebased) taxes distort the intertemporal margin in the same way, discouraging the accumulation of assets. Capital taxes also lead to an outflow of capital from the jurisdiction that levies them, while asset taxes do not. This makes capital taxes more distortionary than asset taxes, rendering them a less attractive source of revenue. Consequently, if a government has a choice between raising revenue by levying an asset income tax and a capital income tax, it always chooses to tax assets rather than capital, because the former comes closer to being a lump-sum tax than the latter.

The point here is not that a government with access to residence-based taxes will never tax capital at source; the point is that no government will tax capital at source in order to raise revenue. It will not because revenue can be raised at a lower cost by taxing asset income. It may nevertheless tax capital at source in order to manipulate the intertemporal terms of trade, but this only happens in an economy where one country is a capital exporter and hence at least one other an importer. The latter of course does not happen if the countries are symmetric so that there are no capital flows in equilibrium.

Moreover, in an economy where capital income is not taxed at source and where neither country is a capital exporter or importer, source-based capital income taxes are not associated with any externalities (see below for a precise definition of externalities). In that situation, a small flow of capital from one jurisdiction to another, induced by a small change in the capital tax, does not affect welfare in either place. The reason is that, in a situation where capital is, in equilibrium, not taxed at source so that capital is paid its marginal product, receiving a small inflow of capital leaves residents of a country no better and no worse off. In general, the representative native of a competitive economy (with constant returns to scale and diminishing returns to labour and capital separately), is indifferent with respect to a small inflow of capital (the same argument holds for a small inflow of labour). A small inflow of capital leads to a lower marginal product capital, and a higher marginal product of labour, thereby hurting owners of capital and benefiting workers. The total benefit 
to domestic workers and capital owners has to be zero, though, since capital is paid its marginal product. If the residents of a country are identical and the country's net foreign asset position is zero, then the residents benefit as much from a small capital inflow in their capacity as workers as they are hurt in their capacity as capital owners. ${ }^{18}$

A similar argument can be constructed to establish why, in an economy where capital income is not taxed at source and economies are sufficiently symmetric so that capital flows are zero, the externalities associated with residence-based capital income taxes are zero as well. The reason is that a resident of either country is indifferent on the margin with respect to an increase in the world capital stock, keeping her own wealth constant. That is, if residents of country 1 accumulate a bit more or a bit less savings, that is a matter of indifference to residents of country 2. So if the government of country 1 raises or cuts the residence based capital income tax slightly, this will have no first-order effect on the welfare of residents of country 2.

The conclusion, then, is that, in an economy where (i) both source-based and residence-based capital taxes are available and (ii), jurisdictions are sufficiently symmetric that there are no capital flows between them in equilibrium, the equilibrium is such that (a) source-based capital income taxes are not used and (b) residencebased capital income taxes are set exactly as they would be in a closed economy, rendering capital mobility irrelevant.

\subsection{Externalities}

In Gross et al. (2017) we identified the cross-border externality from source-based capital taxes when residence-based capital taxes are not available. In order to facilitate a comparison, we restrict our attention here to the case of two countries, "home" and "foreign", where variables associated with the "home" country are de-

\footnotetext{
${ }^{18}$ Residents are not indifferent with respect to a large inflow, however, since the NFAP would then be negative, and foreigners would bear part of the burden of lower capital income.
} 
noted by $h$ and the foreign country by $f$. For instance, $c_{t}^{h}$ is per capita consumption at home and $c_{t}^{f}$ is consumption abroad. Meanwhile, $\theta_{t}^{h}$ is the Lagrange multiplier of the home government's problem associated with the home house households' period t budget constraint and $\theta_{t}^{f}$ is the Lagrange multiplier of the home government's problem associated with the foreign households' period t budget constraint. ${ }^{19}$

We show here that the externalities associated with source-based capital taxes in the context of a hybrid system (indicated with $\mathrm{H}$ ) are very different from their counterparts in a source-based only system (indicated by $S$ ): the fiscal externality vanishes. On the other hand, they are very similar to the externalities associated with residence-based capital taxes.

As in Gross et al. (2017), we define the period $t$ externality associated with a tax as the effect on domestic welfare of a marginal change in the foreign government's source or residence-based capital tax rate at some date $t$, where the foreign government offsets the change in revenues by adjusting its bonds in each period and the labour tax at date $t$ to balance its budget constraint. ${ }^{20}$ It is thus a well-defined deviation from the optimal policy of the foreign government, feasible from its point of view. Meanwhile, the home government, consistently with our equilibrium concept, responds by automatically adjusting its governments spending in period $t$ to preserve government budget balance. Notice, however, that this marginal adjustment does not matter for home welfare because government spending is already optimal. It follows that the externality we define here would be exactly the same under the social equilibrium concept. In any case, the externality does take into account

\footnotetext{
${ }^{19}$ Notice, again, that we will never have occasion to refer explicitly to the Lagrange multipliers of the foreign government's problem, though of course they exist in the background and may differ from those of the home government's problem.

${ }^{20} \mathrm{An}$ increase in foreign capital taxes at time $t$ leads to an increase in tax revenues in that time period, and it also changes the entire sequence of prices (such as $r_{t}$ ) and private-sector choices (such as $a_{t}^{f}$ and $a_{t}^{h}$ ). The foreign government budget constraint would thus not hold with equality in any time period. To analyze deviations that are feasible from the foreign government's point of view, we therefore adjust new government bonds $b_{s+1}^{f}$ in every time period $s \geq 0$ and labour taxes $\tau_{n, t}^{f}$ in time period $t$, so that the government budget constraint holds in every period, as well as intertemporally. Changing only government bonds in every period, but not labour taxes at time $t$ would lead to a total increase in tax revenues. If we only changed labour taxes at time $t$, then the foreign government budget constraint in period $t-1$, for example, would not hold with equality.
} 
how the foreign government's policy change affects the home government's budget constraints; notice below, in Equation (31), that the Lagrange multipliers associated with these constraints appear in the equation for the externality.

Taking the differential (or approximating the discrete change) of home utility with respect (in response) to the foreign source-based capital tax deviation, we find the externality $E_{H}\left(\tau_{k, t}^{f}\right)$ associated with source-based capital taxes at time $t$ to be given by

$$
E_{H}\left(\tau_{k, t}^{f}\right)=-\gamma_{t}^{f} r_{t}^{f} \Delta \tau_{k, t}^{f}-w_{t}^{f}\left(\theta_{t}^{f} n_{t}^{f}+\mu_{t}^{f} u_{c, t}^{f}\right) \Delta \tau_{n, t}^{f}-\sum_{s=1}^{\infty} \beta^{s-t} \chi^{f} \omega_{s} \Delta b_{s}^{f} .
$$

Using the first-order conditions with respect to $R_{t}$ and $\tau_{t}^{k}$, this becomes

$$
\begin{aligned}
E_{H}\left(\tau_{k, t}^{f}\right)= & -r_{t}^{f}\left[\psi_{t}\left(a_{t}^{h}-k_{t}^{h}-b_{t}^{h}\right)-\left(\psi_{t}-\theta_{t}^{h}\right) a_{t}^{h}\left(1-\tau_{a, t}^{h}\right)+\theta_{t}^{f} a_{t}^{f}\left(1-\tau_{a, t}^{f}\right)\right. \\
& \left.+\zeta_{t-1}^{h} u_{c, t}^{h}\left(1-\tau_{a, t}^{h}\right)+\zeta_{t-1}^{f} u_{c, t}^{f}\left(1-\tau_{a, t}^{f}\right)+\phi_{t}\left(1-\tau_{a, t}^{h}\right)\right] \Delta \tau_{k, t}^{f} \\
& -w_{t}^{f}\left(\theta_{t}^{f} n_{t}^{f}+\mu_{t}^{f} u_{c, t}^{f}\right) \Delta \tau_{n, t}^{f}-\chi^{f} \sum_{s=1}^{\infty} \beta^{s-t} \omega_{s} \Delta b_{s}^{f} .
\end{aligned}
$$

For notational convenience, we have written this for any time period $t$ and define $\zeta_{-1}^{i} \equiv 0$ for $i=\{h, f\}$. From here one could derive precisely the externalities we had identified in Gross et al. (2017), including the familiar fiscal externality represented by the term $r_{t}^{f}\left(\psi_{t}-\theta_{t}^{h}\right) a_{t}^{h}\left(1-\tau_{a, t}^{h}\right)$, by setting $\tau_{a, t}^{i}=0$. But we can also use the firstorder condition with respect to $\tau_{\mathrm{a}, \mathrm{t}}$ to determine how the externality changes in the hybrid system:

$$
\begin{array}{r}
E_{H}\left(\tau_{k, t}^{f}\right)=-r_{t}^{f}\left[\psi_{t}\left(a_{t}^{h}-k_{t}^{h}-b_{t}^{h}\right)+\theta_{t}^{f} a_{t}^{f}\left(1-\tau_{a, t}^{f}\right)+\zeta_{t-1}^{f} u_{c, t}^{f}\left(1-\tau_{a, t}^{f}\right)\right] \Delta \tau_{k, t}^{f} \\
-w_{t}^{f}\left(\theta_{t}^{f} n_{t}^{f}+\mu_{t}^{f} u_{c, t}^{f}\right) \Delta \tau_{n, t}^{f}-\sum_{s=1}^{\infty} \beta^{s-t} \chi^{f} \omega_{s} \Delta b_{s}^{f} .
\end{array}
$$


We rewrite this, using the capital-market clearing condition, as

$$
\begin{aligned}
E_{H}\left(\tau_{k, t}^{f}\right)= & \underbrace{-r_{t}^{f}\left(1-\tau_{a, t}^{f}\right) \zeta_{t-1}^{f} u_{c, t}^{f} \Delta \tau_{k, t}^{f}}_{\text {Savings Externality }} \\
& \underbrace{+r_{t}^{f}\left(\psi_{t}-\frac{\chi^{h}}{\chi^{f}} \theta_{t}^{f}\right)\left(k_{t}^{h}+b_{t}^{h}-a_{t}^{h}\right) \Delta \tau_{k, t}^{f}}_{\text {Terms of Trade Externality }} \\
& \underbrace{-\left(w_{t}^{f} \mu_{t}^{f} u_{c, t}^{f}+\theta_{t}^{f}\left(w_{t}^{f} n_{t}^{f}+r_{t}^{f}\left(k_{t}^{f}+b_{t}^{f}-\tau_{a, t}^{f} a_{t}^{f}\right) \frac{\Delta \tau_{k, t}^{f}}{\Delta \tau_{n, t}^{f}}\right)\right) \Delta \tau_{n, t}^{f}}_{\text {Doreign Labour Externality }} \\
& \underbrace{\left.-\sum_{s=1}^{\infty} \beta^{s-t} \omega_{s} \chi^{f} \Delta b_{s}^{f}\right\} .}_{\text {Debt Externality }}
\end{aligned}
$$

We now describe these externalities briefly: The Savings Externality results from the fact that the foreign government does not take into account that an increase in its capital tax will negatively affect the home government through reduced global savings (and hence a smaller global capital stock). A higher capital tax reduces the world-wide rate of return and thereby diminishes savings. The key is the Lagrange multiplier of the household's intertemporal optimality condition, $\zeta_{t-1}^{f}$. The lower global rate of return due to higher capital taxes also benefits borrowers and hurts lenders, so there is a positive Terms of Trade Externality when $k_{t}^{h}+b_{t}^{h}>a_{t}^{h}$ and a negative one when $k_{t}^{h}+b_{t}^{h}<a_{t}^{h} \cdot{ }^{21}$ The next two externalities are more subtle. When the foreign government increases its source-based taxes at time $t$, then new debt issues $b_{s+1}^{f}$ in all periods $s=0,1 \ldots, \infty$ adjust, as well as labour taxes at time $t$. Because changes in capital taxes at any time period change the entire sequence of prices and private-sector choices, this is necessary to satisfy the government budget constraint in all periods; moreover, labour taxes decrease to satisfy the intertemporal budget constraint. The foreign government does not take into account how these changes in its debt and labour taxes affect the home government, whence the Debt and For-

\footnotetext{
${ }^{21}$ The $\theta_{t}^{f}$ appears in this term because the home government also values resources that the foreign households lose/gain due to the changing terms of trade; $\theta_{t}^{f}$ may be positive or negative.
} 
eign Labour Externality. For the latter, a reduction in foreign labour taxes implies that foreign households work more (see the term with Lagrange multiplier $\mu_{\mathrm{t}}^{\mathrm{f}}$, which is for the foreign household's optimal labour-leisure tradeoff). The foreign household may also have more or less resources left after the shift from labour to capital taxes, in net terms this is $-w_{t}^{f} n_{t}^{f} \Delta \tau_{n, t}^{f}-r_{t}^{f}\left(k_{t}^{f}+b_{t}^{f}-\tau_{a, t}^{f} a_{t}^{f}\right) \Delta \tau_{k, t}^{f}$. Note that the entire term would be zero if there were no change in the relative size of the tax bases (of labour and both types of capital taxes). In general, the term should be small, because the foreign government raises the same amount of tax revenues and merely shifts the composition of its taxes, especially since we consider a small change from the optimal equilibrium policy. The Debt Externality arises because an increase (a decrease) in foreign government debt leaves less (more) savings in global capital markets for capital and domestic debt; the foreign government takes this effect of course into account when making its decisions, but not how it affects the domestic government. For ease of reference, we restate here the externality $E_{S}\left(\tau_{k, t}^{f}\right)$ associated with sourcebased capital taxes when residence-based capital taxes are not available, as in Gross et al. (2017), but in the notation of the present paper:

$$
\begin{aligned}
E_{S}\left(\tau_{k, t}^{f}\right)= & \underbrace{-r_{t}^{f}\left(\zeta_{t-1}^{h} u_{c, t}^{h}+\zeta_{t-1}^{f} u_{c, t}^{f}\right) \Delta \tau_{k, t}^{f}}_{\text {Savings Externality }} \\
& \underbrace{+r_{t}^{f}\left(\psi_{t}-\theta_{t}^{h}\right) a_{t}^{h} \Delta \tau_{k, t}^{f}}_{\text {Fiscal Externality }} \\
& \underbrace{+r_{t}^{f}\left(\psi_{t}-\frac{\chi^{h}}{\chi^{f}} \theta_{t}^{f}\right)\left(k_{t}^{h}+b_{t}^{h}-a_{t}^{h}\right) \Delta \tau_{k, t}^{f}}_{\text {Terms of Trade Externality }} \\
& \underbrace{-\left(w_{t}^{f} \mu_{t}^{f} u_{c, t}^{f}+\theta_{t}^{f}\left(w_{t}^{f} n_{t}^{f}+r_{t}^{f}\left(k_{t}^{f}+b_{t}^{f}\right) \frac{\Delta \tau_{k, t}^{f}}{\Delta \tau_{n, t}^{f}}\right)\right) \Delta \tau_{n, t}^{f}}_{\text {Debt Externality }}
\end{aligned}
$$


We can note the following two main differences:

1. The fiscal externality completely disappears when residence-based capital taxes are available-this is the most important difference. Governments use source-based capital income taxes only to manipulate the intertemporal terms of trade, not to raise revenues, because it is more efficient to raise revenues through residence-based taxes. The reason is that residence-based taxes distort only savings, whereas source-based taxes distort savings and the allocation of capital across jurisdictions. Thus, when foreign source-based taxes increase, leading to an inflow of capital into the home country, then this does not relevantly affect the domestic tax base, since any tax revenues from source-based taxes (if they are non-zero) are purely incidental.

2. The savings externality when residence-based capital taxes are available stems only from the foreign households (the term with $\zeta_{t-1}^{f}$ ) and not from the home households: the term with $\zeta_{t-1}^{h}$ has disappeared. This is because the home government can perfectly determine the rate of return of the home consumer through residence-based taxes, while the source-based tax only does so imperfectly. Of course $r_{t}^{f}$ is also multiplied by $1-\tau_{a, t}^{f}$ as the rate of return on savings is $r_{t}^{f}\left(1-\tau_{k, t}^{f}\right)\left(1-\tau_{a, t}^{f}\right)$.

In addition, a minor difference is in the foreign-labour externality, with the additional term $r_{t}^{f} \tau_{a, t}^{f} \theta_{t}^{f} a_{t}^{f} \Delta \tau_{k, t}^{f}$. This stems from the fact that higher capital taxes reduce the tax base for asset taxes.

It is also instructive to consider the externality from residence-based capital taxes, i.e. $E_{H}\left(\tau_{a, t}^{f}\right)$, and how it differs from the externality from source-based taxes (the 
derivation is straightforward and similar to the previous one):

$$
\begin{aligned}
E_{H}\left(\tau_{a, t}^{f}\right)= & \underbrace{-r_{t}^{f}\left(1-\tau_{k, t}^{f}\right) \zeta_{t-1}^{f} u_{c, t}^{f} \Delta \tau_{a, t}^{f}}_{\text {Savings Externality }} \\
& \underbrace{\left.-\left(w_{t}^{f} \mu_{t}^{f} u_{c, t}^{f}+\theta_{t}^{f}\left(w_{t}^{f} n_{t}^{f}+r_{t}^{f}\left(1-\tau_{k, t}^{f}\right) a_{t}^{f}\right) \frac{\Delta \tau_{a, t}^{f}}{\Delta \tau_{n, t}^{f}}\right)\right) \Delta \tau_{n, t}^{f}}_{\text {Foreign labour Externality }} \\
& \underbrace{\left.-\sum_{s=1}^{\infty} \beta^{s-t} \omega_{t} \chi^{f} \Delta b_{s}^{f}\right\} .}_{\text {Debt Externality }}
\end{aligned}
$$

In a symmetric environment, when $k_{t}^{h}+b_{t}^{h}=a_{t}^{h}$ (and of course $k_{t}^{f}+b_{t}^{f}=a_{t}^{f}$ ), the expressions $E_{H}\left(\tau_{k, t}^{f}\right)$ and $E_{H}\left(\tau_{a, t}^{f}\right)$ are exactly the same, except that every $\tau_{a, t}^{f}$ is switched for $\tau_{k, t}^{f}$ and vice versa. ${ }^{22}$ It is only with per-capita asymmetries and non-zero net foreign asset positions that the terms of trade externality really distinguishes the two types of externalities. This also follows of course from our previous result that all externalities are zero when countries are symmetric (since $\gamma_{t}^{f}=0$ ).

\section{Numerical results}

In this section we investigate the quantitative implications of the model for a range of parameter values. We view this as an exercise in quantitative theory, where we parameterize the model so as to make the results broadly speaking empirically relevant. The goal is to highlight the mechanisms at play in this form of tax competition, not to account for any specific historical episode. For computational and expositional ease we again confine our attention to a two-country world.

First, we describe the calibration of a scenario with symmetric countries. Second, we exhibit optimal fiscal policy for a closed economy to establish a baseline and contrast

\footnotetext{
${ }^{22}$ To see this, note that $r_{t}^{f}\left(1-\tau_{k, t}^{f}\right) a_{t}^{f}$ is then equal to $r_{t}^{f}\left(k_{t}^{f}+b_{t}^{f}-\tau_{k, t}^{f} a_{t}^{f}\right)$.
} 
it with the results we obtain in an open economy, once with only source-based capital taxes and then with both source and residence-based ones. Third, we introduce asymmetries which highlight when and how optimal policy in an open economy differs from a closed economy. We show our main results concerning capital taxes in table format in the paper, and we relegate figures to Appendix D.

\subsection{Parameterization}

For the parametrization we use a model economy in steady state (which we call the "pre-initial steady state") with a zero net foreign asset position, satisfying all the government's optimality conditions, except that government debt is exogenously given. In particular, the "pre-initial steady state" satisfies all the constraints in the planning problem (13), as well as the first-order conditions of its choice variables, except for bonds $b_{t+1}^{j}$. We impose for all variables that they are equal in all periods, so $\zeta_{t-1}^{j}=\zeta_{t}^{j}$ for example. See Appendix B for further details. It does not matter whether this pre-initial steady state is that of a closed or an open economy where the NFAP is zero.

We assume a Cobb-Douglas production function,

$$
F\left(k_{t}, n_{t}\right)=Z k_{t}^{\alpha} n_{t}^{1-\alpha}-\delta k_{t} .
$$

We set $Z=1.0$, the capital share $\alpha=0.35$, and the depreciation rate to $\delta=0.08$. The utility functions take the form $u\left(c_{t}, n_{t}\right)=\ln \left(c_{t}\right)-\rho n_{t}^{\sigma}$ and $v\left(g_{t}\right)=\Gamma \ln \left(g_{t}\right)$. We choose $\sigma=3$ in order for the Frisch labour-supply elasticity to be 0.5 . The subjective discount factor, $\beta$, is set equal to 0.9615 so that the annual return to capital (net of depreciation and taxes) in the pre-initial steady state is $4.0 \%$. We then calibrate the remaining parameters $(\rho=6.13$ and $\Gamma=0.74$ in the utility function) and initial government debt $\left(b_{0}=0.36\right)$ so that hours worked are 0.33 , government debt is $60 \%$ of GDP, and government revenues are $35 \%$ of GDP in the pre-initial steady state. Initial total assets held by households $\left(a_{0}=2.09\right)$ are determined as the sum of government debt and capital in each country. The target that hours worked are 
0.33 follows convention, but it is inconsequential, as it merely determines the unit in which hours worked are measured. In the OECD, government revenues were roughly $35 \%$ on average in 2016 . Since we do not distinguish between transfers and government purchases, we calibrate the model from the revenue side.

\subsection{Symmetric environment}

A result in Atkeson et al. (1999) applies to our closed economy model. The result says that the upper limit on capital taxes binds for a finite number of periods, after which we have a non-zero capital tax for exactly one more period, followed by zero asset taxes. The results we present here for a closed economy are thus not new or of any particular importance in themselves; the purpose they serve here is merely to establish a reference point to which we can compare our new findings in an open economy. We first show in Table 1 a numerical verification of our most important analytic result: taxes and allocations of symmetric countries, when capital can flow freely across the border (allowing for residence-based taxes), are exactly identical to the ones in a closed economy. Moreover, the overall externality is zero (see Figure 2). 
Capital taxes when countries are symmetric

\begin{tabular}{|c|c|c|c|c|c|c|c|}
\hline \multirow[b]{2}{*}{ Period } & \multicolumn{3}{|c|}{ Closed economies } & \multicolumn{3}{|c|}{ Open economy } & \multirow[b]{2}{*}{$\tau_{\mathrm{k}}^{\mathrm{f}}$} \\
\hline & $\tau_{a}^{h}$ & $\tau_{a}^{f}$ & $\tau_{\mathrm{a}}^{\mathrm{h}}$ & $\tau_{a}^{f}$ & NFAP & $\tau_{k}^{h}$ & \\
\hline 0 & 1.00 & 1.00 & 1.00 & 1.00 & 0.00 & 0.00 & 0.00 \\
\hline 1 & 1.00 & 1.00 & 1.00 & 1.00 & 0.00 & 0.00 & 0.00 \\
\hline 2 & 1.00 & 1.00 & 1.00 & 1.00 & 0.00 & 0.00 & 0.00 \\
\hline 3 & 1.00 & 1.00 & 1.00 & 1.00 & 0.00 & 0.00 & 0.00 \\
\hline 4 & 1.00 & 1.00 & 1.00 & 1.00 & 0.00 & 0.00 & 0.00 \\
\hline 5 & 1.00 & 1.00 & 1.00 & 1.00 & 0.00 & 0.00 & 0.00 \\
\hline 6 & 1.00 & 1.00 & 1.00 & 1.00 & 0.00 & 0.00 & 0.00 \\
\hline 7 & 1.00 & 1.00 & 1.00 & 1.00 & 0.00 & 0.00 & 0.00 \\
\hline 8 & 1.00 & 1.00 & 1.00 & 1.00 & 0.00 & 0.00 & 0.00 \\
\hline 9 & 0.16 & 0.16 & 0.16 & 0.16 & 0.00 & 0.00 & 0.00 \\
\hline 10 & 0.00 & 0.00 & 0.00 & 0.00 & 0.00 & 0.00 & 0.00 \\
\hline$\vdots$ & $\vdots$ & $\vdots$ & $\vdots$ & $\vdots$ & $\vdots$ & $\vdots$ & \\
\hline 30 & 0.00 & 0.00 & 0.00 & 0.00 & 0.00 & 0.00 & 0.00 \\
\hline$\vdots$ & $\vdots$ & $\vdots$ & $\vdots$ & $\vdots$ & $\vdots$ & $\vdots$ & \\
\hline 50 & 0.00 & 0.00 & 0.00 & 0.00 & 0.00 & 0.00 & 0.00 \\
\hline
\end{tabular}

Table 1: $\tau_{a}^{h}$ and $\tau_{k}^{h}$ are the home residence- and source-based capital tax rates, $\tau_{a}^{f}$ and $\tau_{k}^{f}$ are the foreign counterparts. NFAP is the net foreign asset position from the point of view of the home country, expressed as a fraction of home output.

We contrast this with the results we obtain when we do not allow for residencebased taxes, the classic case of tax competition, in Table 2 and Figure $1 .^{23}$ Even though the two countries are symmetric, the positive externality of source-based

\footnotetext{
${ }^{23}$ These results are very similar to the ones from our previous work, Gross et al. (2017). Also note that there is no expropriation of capital in the first period $t=0$, because capital is mobile in each period, including time period 0 . The stock of assets in each country (and thus the global capital stock) is determined one period in advance, but at the beginning of each period investors decide where to allocate capital. Hence, $\sum_{i=1}^{m} \chi^{i} k_{0}^{i}$ is given, but $k_{0}^{i}$ is not.
} 
capital taxes (in the absence of savings taxes) leads to a significant reduction in capital taxes in the short run and to a protracted convergence to zero in the long run. Comparing a closed to an open economy, there are substantial welfare losses, equivalent to the loss of $1.19 \%$ of private consumption in each period. This welfare loss is of course due to the externalities associated with tax competition (see Figure 2), and the fact that there are no offsetting gains from trade in capital since the countries are symmetric.

Capital taxes with symmetric countries-source-based taxes only

\begin{tabular}{ccccccr}
\hline \hline & \multicolumn{3}{c}{ Closed economies } & \multicolumn{3}{c}{ Open economy } \\
Period & $\tau_{\mathrm{k}}^{\mathrm{h}}$ & $\tau_{\mathrm{k}}^{\mathrm{f}}$ & NFAP & $\tau_{\mathrm{k}}^{\mathrm{h}}$ & $\tau_{\mathrm{k}}^{\mathrm{f}}$ \\
& & & & & \\
0 & 1.00 & 1.00 & 0.00 & 0.39 & 0.39 \\
1 & 1.00 & 1.00 & 0.00 & 0.36 & 0.36 \\
2 & 1.00 & 1.00 & 0.00 & 0.33 & 0.33 \\
3 & 1.00 & 1.00 & 0.00 & 0.30 & 0.30 \\
4 & 1.00 & 1.00 & 0.00 & 0.27 & 0.27 \\
5 & 1.00 & 1.00 & 0.00 & 0.25 & 0.25 \\
6 & 1.00 & 1.00 & 0.00 & 0.23 & 0.23 \\
7 & 1.00 & 1.00 & 0.00 & 0.21 & 0.21 \\
8 & 1.00 & 1.00 & 0.00 & 0.19 & 0.19 \\
9 & 0.16 & 0.16 & 0.00 & 0.17 & 0.17 \\
10 & 0.00 & 0.00 & 0.00 & 0.16 & 0.16 \\
$\vdots$ & $\vdots$ & $\vdots$ & $\vdots$ & $\vdots$ & $\vdots$ \\
30 & 0.00 & 0.00 & 0.00 & 0.02 & 0.02 \\
$\vdots$ & $\vdots$ & $\vdots$ & $\vdots$ & $\vdots$ & $\vdots$ \\
50 & 0.00 & 0.00 & 0.00 & 0.00 & 0.00 \\
\hline & & & & &
\end{tabular}

Table 2: $\tau_{a}^{h}$ and $\tau_{k}^{h}$ are the home residence- and source-based capital tax rates, $\tau_{a}^{f}$ and $\tau_{k}^{f}$ are the foreign counterparts. NFAP is the net foreign asset position from the point of view of the home country, expressed as a fraction of home output. 
Our main result has important ramifications for tax competition: the famous race to the bottom in capital taxes known from the received literature on tax competition seems to rely entirely on the inability to tax the initial asset holdings of domestic residents through residence-based taxes. ${ }^{24}$ As shown before in Gross (2014) and Gross (2015a), steady-state capital taxes are the same whether the economy is open or closed, and tax competition is thus not an issue in the long run. If governments are able to tax initial asset holdings through residence-based taxes as in this paper, then tax competition has no effects whatsoever, even in the short run. The welfare gains/losses from an open economy as compared to a closed economy are thus zero.

\subsection{Asymmetries}

As we have shown in our theoretical description of externalities, source-based taxes have the same externality as residence-based taxes as long as the net foreign asset position is zero. In this section, we introduce some asymmetries which highlight how countries use source-based taxes to manipulate the terms of trade. We only change one parameter/initial value at a time and do not recalibrate the remaining values. This allows for a clean evaluation of the importance of different dimensions of heterogeneity.

Differences in the Initial Asset Position In this scenario, we alter the initial asset position of the home country so that it is $20 \%$ higher than in the foreign country. Therefore, if everything else were the same (including the endogenous variables), then the return to capital at home would be lower than abroad; as a result, capital will flow from the home to the foreign country and the NFAP is positive. The home country thus aims to increase the price of its export good (capital), and hence re-

\footnotetext{
${ }^{24}$ This inability to tax initial assets is also reflected in the path of government debt, see Figure 3. With access to source-based capital taxes only, the government is able to reduce its debt somewhat in the short run, but keeps a substantial positive debt burden in the long run. In the hybrid system, the government uses asset taxes to completely pay off its original debt and even accumulate some government assets (negative debt).
} 
duces the source-based tax rate to increase the global rate of return, $R_{t}$. The foreign country has the exact opposite incentives and thus increases its source-based tax rate. The differences in the tax rates lead to a partial reversal of capital flows. We show the results in Table 3 and Figure 4.

Capital taxes when home country has greater initial assets

\begin{tabular}{ccccccccc}
\hline \hline \multicolumn{5}{c}{ Closed economies } & \multicolumn{5}{c}{ Open economy } \\
Period & $\tau_{\mathrm{a}}^{\mathrm{h}}$ & $\tau_{\mathrm{a}}^{\mathrm{f}}$ & $\tau_{\mathrm{a}}^{\mathrm{h}}$ & $\tau_{\mathrm{a}}^{\mathrm{f}}$ & NFAP & $\tau_{\mathrm{k}}^{\mathrm{h}}$ & $\tau_{\mathrm{k}}^{\mathrm{f}}$ \\
& & & & & & & \\
0 & 1.00 & 1.00 & 1.00 & 1.00 & 0.15 & -0.16 & 0.13 \\
1 & 1.00 & 1.00 & 1.00 & 1.00 & 0.14 & -0.14 & 0.11 \\
2 & 1.00 & 1.00 & 1.00 & 1.00 & 0.13 & -0.12 & 0.10 \\
3 & 1.00 & 1.00 & 1.00 & 1.00 & 0.12 & -0.11 & 0.09 \\
4 & 1.00 & 1.00 & 1.00 & 1.00 & 0.12 & -0.09 & 0.08 \\
5 & 1.00 & 1.00 & 1.00 & 1.00 & 0.11 & -0.08 & 0.07 \\
6 & 1.00 & 1.00 & 1.00 & 1.00 & 0.10 & -0.07 & 0.06 \\
7 & 1.00 & 1.00 & 1.00 & 1.00 & 0.09 & -0.06 & 0.06 \\
8 & 1.00 & 1.00 & 1.00 & 1.00 & 0.09 & -0.06 & 0.05 \\
9 & 1.00 & 0.16 & 1.00 & 0.27 & 0.09 & -0.03 & 0.05 \\
10 & 0.77 & 0.00 & 0.62 & -0.04 & 0.10 & -0.02 & 0.04 \\
11 & 0.00 & 0.00 & 0.02 & -0.02 & 0.11 & -0.02 & 0.02 \\
12 & 0.00 & 0.00 & 0.02 & -0.02 & 0.11 & -0.02 & 0.02 \\
$\vdots$ & $\vdots$ & $\vdots$ & $\vdots$ & $\vdots$ & $\vdots$ & $\vdots$ & $\vdots$ \\
30 & 0.00 & 0.00 & 0.00 & -0.00 & 0.10 & -0.00 & 0.00 \\
$\vdots$ & $\vdots$ & $\vdots$ & $\vdots$ & $\vdots$ & $\vdots$ & $\vdots$ & $\vdots$ \\
50 & 0.00 & 0.00 & 0.00 & -0.00 & 0.10 & -0.00 & 0.00 \\
\hline \hline
\end{tabular}

Table 3: $\tau_{a}^{h}$ and $\tau_{k}^{h}$ are the home residence- and source-based capital tax rates, $\tau_{a}^{f}$ and $\tau_{k}^{f}$ are the foreign counterparts. NFAP is the net foreign asset position from the point of view of the home country, expressed as a fraction of home output. 
One can also observe that the home country taxes assets more than the foreign country in a closed economy, which is unsurprising given that its initial capital stock is larger. These differences also carry over to an open economy and the profile of savings taxes is remarkably similar to the closed economy. The home country has lower savings taxes in period 10 in an open compared to a closed economy, but then compensates with taxes slightly above zero in the following few periods. The foreign country has slightly higher savings taxes in period 9, and compensates by slightly negative taxes in the ensuing periods. We are not showing the labour taxes here, but in the long run they are higher for the country with the larger initial asset position. This can be explained by the fact that domestic households are richer and therefore provide less labour supply, which implies higher labour taxes. Domestic government consumption is initially higher, but converges to almost exactly the same level as abroad, while domestic debt is always larger (except for period zero, of course).

There are small, but positive welfare effects of opening up capital markets, of $0.051 \%$ in the home country and $0.059 \%$ in the foreign country (all welfare changes are in terms of private consumption equivalence each period). The decomposition of the externalities is shown in Figure 5: There is a negative terms-of-trade externality, leading to a total negative externality in the short run. In the long run a positive savings externality counteracts this effect, so that the total externality converges to zero. Note that the savings externality has to equal zero while asset taxes are at $100 \%$ : a change in $\tau_{k}^{f}$ cannot have any effect on savings then.

The units in which externalities are measured deserve explicit comment. Firstly, the externalities are measured in current value, discounted back to the period in which the intervention occurs, not to period 0. Secondly, they are the derivative of the period utility function with respect to the relevant tax rate. Because the period utility function is additively separable between consumption and labour and because it is logarithmic in consumption, this derivative has a very concrete interpretation. It is the percentage change in the consumption equivalent with respect to the percentage point change in the relevant tax rate. 
The externality from the perspective of the foreign country is the (almost exact) mirror image: a positive terms-of-trade externality and a negative savings externality. The two countries would thus never agree to jointly increase or decrease sourcebased capital taxes. The same applies in all of the following cases.

Differences in Government Spending Countries may also differ in their tastes for government spending. In this exercise, we set the parameter $\Gamma^{\mathrm{h}}$ to $0.30\left(\Gamma^{\mathrm{f}}\right.$ stays at 0.74 ), so that the ratio of government spending to GDP in the pre-initial steady state would be 0.20 in the home economy (as opposed to 0.35 in the foreign economy). We show the results in Table 4 and Figure 6. 
Capital taxes when home country government spends less

\begin{tabular}{|c|c|c|c|c|c|c|c|}
\hline \multirow[b]{2}{*}{ Period } & \multicolumn{3}{|c|}{ Closed economies } & \multicolumn{3}{|c|}{ Open economy } & \multirow[b]{2}{*}{$\tau_{k}^{f}$} \\
\hline & $\tau_{a}^{h}$ & $\tau_{a}^{f}$ & $\tau_{a}^{h}$ & $\tau_{a}^{f}$ & NFAP & $\tau_{\mathrm{k}}^{\mathrm{h}}$ & \\
\hline 0 & 1.00 & 1.00 & 1.00 & 1.00 & -0.02 & -0.01 & 0.00 \\
\hline 1 & 1.00 & 1.00 & 1.00 & 1.00 & -0.01 & -0.01 & 0.01 \\
\hline 2 & 1.00 & 1.00 & 1.00 & 1.00 & -0.00 & -0.01 & 0.01 \\
\hline 3 & 1.00 & 1.00 & 1.00 & 1.00 & 0.01 & -0.02 & 0.01 \\
\hline 4 & 1.00 & 1.00 & 1.00 & 1.00 & 0.02 & -0.02 & 0.02 \\
\hline 5 & 0.59 & 1.00 & 0.62 & 1.00 & 0.03 & -0.03 & 0.02 \\
\hline 6 & 0.00 & 1.00 & 0.04 & 1.00 & 0.05 & -0.04 & 0.01 \\
\hline 7 & 0.00 & 1.00 & 0.04 & 1.00 & 0.06 & -0.04 & 0.01 \\
\hline 8 & 0.00 & 1.00 & 0.04 & 1.00 & 0.07 & -0.04 & 0.01 \\
\hline 9 & 0.00 & 0.16 & 0.02 & 0.16 & 0.08 & -0.02 & 0.02 \\
\hline 10 & 0.00 & 0.00 & 0.02 & -0.02 & 0.08 & -0.02 & 0.02 \\
\hline$\vdots$ & $\vdots$ & $\vdots$ & $\vdots$ & $\vdots$ & $\vdots$ & $\vdots$ & $\vdots$ \\
\hline 30 & 0.00 & 0.00 & 0.00 & -0.00 & 0.07 & -0.00 & 0.00 \\
\hline$\vdots$ & $\vdots$ & $\vdots$ & $\vdots$ & $\vdots$ & $\vdots$ & $\vdots$ & $\vdots$ \\
\hline 50 & 0.00 & 0.00 & 0.00 & -0.00 & 0.07 & -0.00 & 0.00 \\
\hline
\end{tabular}

Table 4: $\tau_{a}^{h}$ and $\tau_{k}^{h}$ are the home residence- and source-based capital tax rates, $\tau_{a}^{f}$ and $\tau_{k}^{f}$ are the foreign counterparts. NFAP is the net foreign asset position from the point of view of the home country, expressed as a fraction of home output.

The home country taxes assets less than the foreign country in a closed economy, because its thirst for tax revenues is smaller and therefore all taxes are lower. Very similarly to the previous case, these differences in savings taxes remain largely intact in an open economy. The NFAP is negative at first, since labour taxes are lower and hence labour supply is higher in the home country, which would lead (offequilibrium) to a higher marginal product of capital, and hence results in an inflow 
of capital. Interestingly, the sign of the NFAP changes and the home country becomes a net exporter of capital. This is because the savings taxes and labour taxes in the home country are lower and domestic households accumulate more assets than their foreign counterparts.

The importance of dynamics is underscored by the sign of the source-based taxes (the magnitude is small): They are always negative for the home country and positive for the foreign country, even though the NFAP changes signs. The intuition is that capital taxes at time $t$ influence the terms of trade not only at time $t$, but also in the other periods through the dynamic capital accumulation effects, as emphasized in our previous work, Gross et al. (2017). Since the NFAP is smaller in magnitude when negative than later when positive, the home country is over time effectively a capital exporter. As before, there are very small but positive welfare gains from capital mobility for both countries; $0.005 \%$ at home and $0.005 \%$ abroad.

The externalities, see Figure 7, reflect the changing sign of the NFAP, so that the total externality follows a u-shaped pattern. At first, the positive terms-of-trade externality implies a positive total externality, then both turn negative, while the total externality converges to zero in the long run, due to the positive savings externality.

Differences in Initial Debt We now consider the case where the home government starts with no initial debt, i.e. we set $b_{0}=0$. In order to keep the initial capital stock constant so that we do not confound the effects with what we observed earlier, we also change the initial home assets $a_{0}$ by the same amount. We show the results in Table 5 and Figure 8. 
Capital taxes when home country has zero initial government debt

\begin{tabular}{crrrrrrrr}
\hline \hline & \multicolumn{6}{c}{ Closed economies } & \multicolumn{5}{c}{ Open economy } \\
Period & $\tau_{\mathrm{a}}^{\mathrm{h}}$ & $\tau_{\mathrm{a}}^{\mathrm{f}}$ & $\tau_{\mathrm{a}}^{\mathrm{h}}$ & $\tau_{\mathrm{a}}^{\mathrm{f}}$ & NFAP & $\tau_{\mathrm{k}}^{\mathrm{h}}$ & $\tau_{\mathrm{k}}^{\mathrm{f}}$ \\
& & & & & & & \\
0 & 1.00 & 1.00 & 1.00 & 1.00 & -0.01 & 0.00 & -0.00 \\
1 & 1.00 & 1.00 & 1.00 & 1.00 & -0.01 & 0.00 & -0.00 \\
2 & 1.00 & 1.00 & 1.00 & 1.00 & -0.00 & -0.00 & 0.00 \\
3 & 1.00 & 1.00 & 1.00 & 1.00 & -0.00 & -0.00 & 0.00 \\
4 & 1.00 & 1.00 & 1.00 & 1.00 & 0.00 & -0.00 & 0.00 \\
5 & 1.00 & 1.00 & 1.00 & 1.00 & 0.01 & -0.01 & 0.01 \\
6 & 1.00 & 1.00 & 1.00 & 1.00 & 0.01 & -0.01 & 0.01 \\
7 & 1.00 & 1.00 & 1.00 & 1.00 & 0.01 & -0.01 & 0.01 \\
8 & 0.12 & 1.00 & 0.14 & 1.00 & 0.02 & -0.01 & 0.01 \\
9 & 0.00 & 0.16 & 0.01 & 0.15 & 0.03 & -0.01 & 0.01 \\
10 & 0.00 & 0.00 & 0.01 & -0.01 & 0.03 & -0.01 & 0.01 \\
$\vdots$ & $\vdots$ & $\vdots$ & $\vdots$ & $\vdots$ & $\vdots$ & $\vdots$ & $\vdots$ \\
30 & 0.00 & 0.00 & 0.00 & -0.00 & 0.02 & -0.00 & 0.00 \\
$\vdots$ & $\vdots$ & $\vdots$ & $\vdots$ & $\vdots$ & $\vdots$ & $\vdots$ & $\vdots$ \\
50 & 0.00 & 0.00 & 0.00 & -0.00 & 0.02 & -0.00 & 0.00 \\
\hline \hline
\end{tabular}

Table 5: $\tau_{\mathrm{a}}^{\mathrm{h}}$ and $\tau_{\mathrm{k}}^{\mathrm{h}}$ are the home residence- and source-based capital tax rates, $\tau_{\mathrm{a}}^{\mathrm{f}}$ and $\tau_{k}^{f}$ are the foreign counterparts. NFAP is the net foreign asset position from the point of view of the home country, expressed as a fraction of home output.

The home country taxes capital less than the foreign country in a closed economy, which stems from the fact that it has lower revenue requirements to finance its initial debt. The time path of savings taxes stays almost exactly the same in an open economy. The NFAP is initially negative, since employment is higher in the home country, and thus the marginal product of capital would be higher if it were not for capital inflows. Similar to the previous case, the NFAP changes signs, for exactly the 
same reasons. It is interesting to note, however, that in this case source-based capital taxes switch signs: domestic rates are initially positive and then turn negative (if very small in magnitude) and vice versa for foreign rates. ${ }^{25}$ The welfare gains are tiny $(0.001 \%$ at home and abroad), as indicated by the small NFAP, but still positive. The externalities, depicted in Figure 9, follow a similar pattern as in the previous exercise, but are smaller in magnitude.

Differences in Economy Size While cross-country differences in terms of the population size $\chi$ or productivity $Z$ (and appropriately rescaling the initial values $a_{0}$ and $b_{0}$ ) lead to quite different tax rates when only source-based taxes are allowed, optimal policy is still the same as in a closed economy when we allow residence-based savings taxes. The reason is that larger economies face a lower elasticity of capital flight with respect to their source-based tax rate, so that they can tax the initial capital stock better with source-based taxes. However, when countries tax initial assets through savings taxes, then capital flight is not an issue and the elasticity of capital supply does not play a role in determining optimal capital taxes.

Differences in population size or productivity do play a role once we introduce them along with other asymmetries. For instance, when one country has larger initial assets and is a larger economy, then the bigger size of its economy allows it to manipulate the terms of trade more in its favor. In Table 6 and Figure 10 we show the results for the case when the home country's initial asset position per capita is $20 \%$ larger than in the symmetric case (as in our earlier exercise) and its population size is twice that of the foreign country.

\footnotetext{
${ }^{25}$ Compared to the previous case shown in Table 4, where the tax rates did not switch signs, the magnitudes of the future NFAPs are lower here.
} 
Capital taxes when home country has a greater population and initial asset position

\begin{tabular}{crrrrrrr}
\hline \hline \multicolumn{7}{c}{ Closed economies } & \multicolumn{5}{c}{ Open economy } \\
Period & $\tau_{\mathrm{a}}^{\mathrm{h}}$ & $\tau_{\mathrm{a}}^{\mathrm{f}}$ & $\tau_{\mathrm{a}}^{\mathrm{h}}$ & $\tau_{\mathrm{a}}^{\mathrm{f}}$ & NFAP & $\tau_{\mathrm{k}}^{\mathrm{h}}$ & $\tau_{\mathrm{k}}^{\mathrm{f}}$ \\
& & & & & & & \\
0 & 1.00 & 1.00 & 1.00 & 1.00 & 0.19 & -0.23 & 0.09 \\
1 & 1.00 & 1.00 & 1.00 & 1.00 & 0.18 & -0.19 & 0.08 \\
2 & 1.00 & 1.00 & 1.00 & 1.00 & 0.17 & -0.17 & 0.07 \\
3 & 1.00 & 1.00 & 1.00 & 1.00 & 0.16 & -0.15 & 0.06 \\
4 & 1.00 & 1.00 & 1.00 & 1.00 & 0.15 & -0.13 & 0.05 \\
5 & 1.00 & 1.00 & 1.00 & 1.00 & 0.14 & -0.11 & 0.05 \\
6 & 1.00 & 1.00 & 1.00 & 1.00 & 0.13 & -0.10 & 0.04 \\
7 & 1.00 & 1.00 & 1.00 & 1.00 & 0.13 & -0.09 & 0.04 \\
8 & 1.00 & 1.00 & 1.00 & 1.00 & 0.12 & -0.07 & 0.03 \\
9 & 1.00 & 0.16 & 1.00 & 0.34 & 0.13 & -0.04 & 0.04 \\
10 & 0.77 & 0.00 & 0.67 & -0.03 & 0.14 & -0.02 & 0.03 \\
$\vdots$ & $\vdots$ & $\vdots$ & $\vdots$ & $\vdots$ & $\vdots$ & $\vdots$ & $\vdots$ \\
20 & 0.00 & 0.00 & 0.01 & -0.00 & 0.14 & -0.01 & 0.00 \\
$\vdots$ & $\vdots$ & $\vdots$ & $\vdots$ & $\vdots$ & $\vdots$ & $\vdots$ & $\vdots$ \\
30 & 0.00 & 0.00 & 0.00 & -0.00 & 0.13 & -0.00 & 0.00 \\
$\vdots$ & $\vdots$ & $\vdots$ & $\vdots$ & $\vdots$ & $\vdots$ & $\vdots$ & $\vdots$ \\
50 & 0.00 & 0.00 & 0.00 & -0.00 & 0.13 & -0.00 & 0.00 \\
\hline \hline
\end{tabular}

Table 6: $\tau_{a}^{h}$ and $\tau_{k}^{h}$ are the home residence- and source-based capital tax rates, $\tau_{a}^{f}$ and $\tau_{k}^{f}$ are the foreign counterparts. NFAP is the net foreign asset position from the point of view of the home country, expressed as a fraction of home output.

In comparison with what we had observed in Table 3 when countries differed in their initial asset position, but not country size, we see the following: The larger country sets higher savings taxes for a longer period of time; they are still at $1 \%$ in period 20. Moreover, the magnitude of source-based taxes is larger for the big- 
ger country and smaller for the other country-the larger country can influence the world-wide rate of return more and uses this market power.

An interesting and potentially important implication of these results is that the cross-border externalities of manipulating the terms of trade are less severe the smaller each country is compared to the rest of the world. For example, if there were a large number of countries of each of two types (with low and high initial assets), then each country would find it difficult to change the global terms of trade and source-based taxes would be zero. This is exactly the opposite of the fiscal externality (with only source-based taxes), which worsens as the number of countries increases, as emphasized by the received tax competition literature. A similar point emerges from Razin and Sadka (1991) in an essentially static model (with an endogenous capital supply), but it bears emphasizing that the current NFAP is not necessarily the relevant statistic when countries manipulate their terms of trade.

The welfare gains from capital mobility are a bit smaller at home $(0.039 \%)$ and a bit larger abroad $(0.064 \%)$ as compared to the case when country size was the same. This naturally follows from the fact that moving one unit of capital (per capita) abroad leads to a larger change in the foreign rate of return when the domestic population is larger. We show the externalities in Figure 11, which follow the same pattern as when only assets per capita differ. The magnitude is smaller, since foreign actions influence the home country less the larger the home country is in relative terms. For the foreign country, the externalities pattern is the mirror image of the home country, but larger in magnitude compared to the case when only assets per capita differ.

\section{Conclusion}

In this paper we explored the implications of allowing residence-based capital taxes in a multi-jurisdiction environment where capital is mobile and endogenously ac- 
cumulated, i.e. a fully dynamic open-economy model. We prove analytically that, in this setting, capital taxes are zero in the long run, whether there are residencebased taxes only or both residence-based and source-based taxes. We thus extend the results by Chamley (1986) for a closed economy, Correia (1996a) for a small open economy, and Gross (2014) for an open economy with source-based taxes only. We also show analytically that the fiscal externality of source-based capital taxes vanishes when we allow for residence-based taxes. Furthermore, the externalities from residence-based and source-based taxes are identical, except for a terms of trade externality from source-based taxes (which is zero when countries differ only, if at all, by population size or productivity). All this is in sharp contrast to our results in Gross et al. (2017), where we only allow for source-based taxes.

Our most surprising result is that governments choose identical fiscal policies in a closed as in an open economy, when countries differ only, if at al, by population size or productivity. In that case, the cross-country externalities are zero in all time periods. What are the implications of this? In our previous work, we found that the cross-country externalities with source-based taxes are zero only in the long run, negative in the medium run, and positive (but smaller than in a static model) in the short run. That is, in a fully dynamic model, source-based tax competition is less grave a problem than in a static world. With residence-based taxes it ceases to be a problem at all. In this respect, we extend earlier work in a pseudo-dynamic twoperiod model, e.g. Bucovetsky and Wilson (1991) and Eggert and Haufler (1999), to an infinite horizon setting.

When countries differ with respect to other features, such as initial assets, preference for government spending, or initial debt, so that net foreign asset positions become non-zero, then governments use source-based taxes to manipulate the intertemporal terms of trade in the short and medium run. This is in consonance with previous results by De Pater and Myers (1994) in a static model with lump-sum taxes and an exogenous labour supply and our results in Gross et al. (2017).

What are the potential policy implications of our work? Our results suggest that 
the problems of integrated capital markets in terms of harmful tax competition are much less severe than one might have thought in light of earlier models. Crossborder externalities only arise when there are asymmetries between countries and therefore also gains from trade in capital. In fact, both countries experienced welfare gains as compared to a closed economy in all our computational experiments, in sharp distinction to the welfare losses when only source-based taxes were allowed. Moreover, all externalities vanish in the long run. Thus we conclude, in light of our analysis, that as information sharing across jurisdictions is enhanced, concerns about the damaging effects of tax competition should fade away.

We end with a few caveats. In order to keep our model tractable and to establish some baseline results in a standard environment, we abstract from several key aspects of fiscal policy. Here are but a few important issues that appear particularly interesting in dynamic models: (i) heterogeneous agents and political economy (cf. Lockwood and Makris, 2006), since the accumulation of wealth plays a major role in determining inequality; (ii) overlapping generations, which generate a different savings motive than with infinitely-lived dynasties (cf. Erosa and Gervais, 2002, vs. Chamley, 1986); (iii) imperfect capital mobility and imperfect trade (cf. Janeba and Wilson, 1999), since barriers to trade and investment are still important and affect savings behaviour. We believe that our approach is flexible and tractable enough to pursue these questions and thus view our paper also as a stepping stone for future research. 


\section{Appendix A: A closed economy}

In a closed economy, we write the Lagrangian of country $j$ as

$$
\begin{aligned}
\mathcal{L}= & \sum_{t=0}^{\infty} \beta^{t}\left\{u^{j}\left(c_{t}^{j}, l_{t}^{j}\right)+v^{j}\left(g_{t}^{j}\right)\right. \\
& +\psi_{t}\left[r_{t}^{j} k_{t}^{j}-\tilde{r}_{t}^{j} k_{t}^{j}+\tau_{a, t}^{j} \tilde{r}_{t}^{j} a_{t}^{j}+\tau_{n, t}^{j} w_{t}^{j} n_{t}^{j}+b_{t+1}^{j}-\left(1+\tilde{r}_{t}^{j}\right) b_{t}^{j}-g_{t}^{j}\right] \\
& +\theta_{t}^{j}\left[\left(1-\tau_{n, t}^{j}\right) w_{t}^{j} n_{t}^{j}+\left[1+\tilde{r}_{t}^{j}\left(1-\tau_{a, t}^{j}\right)\right] a_{t}^{j}-a_{t+1}^{j}-c_{t}^{j}\right] \\
& +\mu_{t}^{j}\left[\left(1-\tau_{n, t}^{j}\right) w_{t}^{j} u_{c, t}^{j}-u_{l, t}^{j}\right] \\
& +\zeta_{t}^{j}\left\{\beta u_{c, t+1}^{j}\left[1+\tilde{r}_{t+1}^{j}\left(1-\tau_{a, t+1}^{j}\right)\right]-u_{c, t}^{j}\right\} \\
& +\omega_{t}\left(a_{t}^{j}-k_{t}^{j}-b_{t}^{j}\right) \\
& \left.+\phi_{t} \tilde{r}_{t}^{j}\left(1-\tau_{a, t}^{j}\right)\right\},
\end{aligned}
$$

with the following set of choice variables:

$$
\tilde{X}=\left\{c_{t}^{j}, n_{t}^{j}, k_{t}^{j}, a_{t+1}^{j}, g_{t}^{j}, b_{t+1}^{j}, \tau_{a, t}^{j}, \tilde{r}_{t}^{j}, \tau_{n, t}^{j}\right\}_{t=0}^{\infty} .
$$

Note that it is not meaningful to distinguish between residence-based and sourcebased taxes in a closed economy. We write the Lagrangian and choice set in this way to highlight the similarities and differences with the open-economy version shown before.

\section{Appendix B: Calibration and the "pre-initial steady state"}

For our calibration, we would like some target moments to be met in a "pre-initial steady state," as outlined in Section 5.1. We do this for a closed economy, so we do not include asset taxes (which are redundant), and drop the country superscripts. Since it is a steady state, variables are time-invariable, and we drop time subscripts. We use subscripts to denote derivatives, for instance we define $r_{k} \equiv \partial r / \partial k$. We 
do not include a first-order condition for government debt $b$, since it always holds in steady state; it does not pin down any additional variables, as $\beta(1+R)-1=0$ has to hold from the household's optimal intertemporal tradeoff. The amount of steady-state debt is determined by initial conditions (i.e. the initial amount of debt). We therefore replace this first-order condition with the condition that government debt in the "pre-initial steady state" is $60 \%$ of GDP.

The system of equations that we solve (numerically) consists of the following elements:

Government budget constraint:

$\tau_{k} r k+\tau_{n} w n-g-b R=0$

Household budget constraint:

$\left(1-\tau_{\mathrm{n}}\right) w \mathrm{n}+\mathrm{Ra}-\mathrm{c}=0$

Household optimal labor-leisure tradeoff:

$u_{c} w\left(1-\tau_{n}\right)+u_{n}=0$

Household optimal intertemporal tradeoff:

$\beta(1+R)-1=0$

Capital-market clearing condition:

$a-k-b=0$

Investor no-arbitrage condition:

$r\left(1-\tau_{k}\right)-R=0$

Government spending first-order condition :

$u_{g}-\psi=0$ 
Labour tax first-order condition :

$\psi w n-\theta w n-\mu u_{c} w=0$

Capital tax first-order condition :

$\psi k-\gamma=0$

Labour first-order condition :

$$
\begin{aligned}
& u_{n}+\psi \tau_{k} k r_{n}+\psi \tau_{n} n w_{n}+\theta\left(1-\tau_{n}\right) n w_{n}+\mu u_{c}\left(1-\tau_{n}\right) w_{n}+\gamma\left(1-\tau_{k}\right) r_{n}+ \\
& \psi \tau_{n} w+\theta\left(1-\tau_{n}\right) w+\mu u_{n n}=0
\end{aligned}
$$

Consumption first-order condition :

$\mathfrak{u}_{c}-\theta+\mu \mathfrak{u}_{c c} \mathcal{w}\left(1-\tau_{\mathfrak{n}}\right)+\operatorname{Ru}_{c c} \zeta=0$

Capital first-order condition :

$\psi \tau_{k} k r_{k}+\psi \tau_{n} n w_{k}+\theta\left(1-\tau_{n}\right) n w_{k}+\mu u_{c}\left(1-\tau_{n}\right) w_{k}+\gamma\left(1-\tau_{k}\right) r_{k}+\psi \tau_{k} r-\omega=0$

Assets first-order condition :

$\theta(1+R)-\theta / \beta+\omega=0$

Interest rate first-order condition :

$-\psi b+\theta a-\gamma+\zeta u_{c}=0$

Target for the net interest rate:

$R-0.04=0$

Target for the government debt to GDP ratio:

$b-0.6 f(k, n)=0$ 
Target for the tax revenues to GDP ratio:

$\tau_{k} r k+\tau_{n} w n-0.35 f(k, n)=0$

Target for hours worked:

$n-1 / 3=0$

Target for the Frisch labour-supply elasticity:

$1 /(\sigma-1)-0.5=0$. 


\section{Appendix C: Figures}

Figure 1. Capital (asset) taxes under the hybrid and source-based system when countries are symmetric

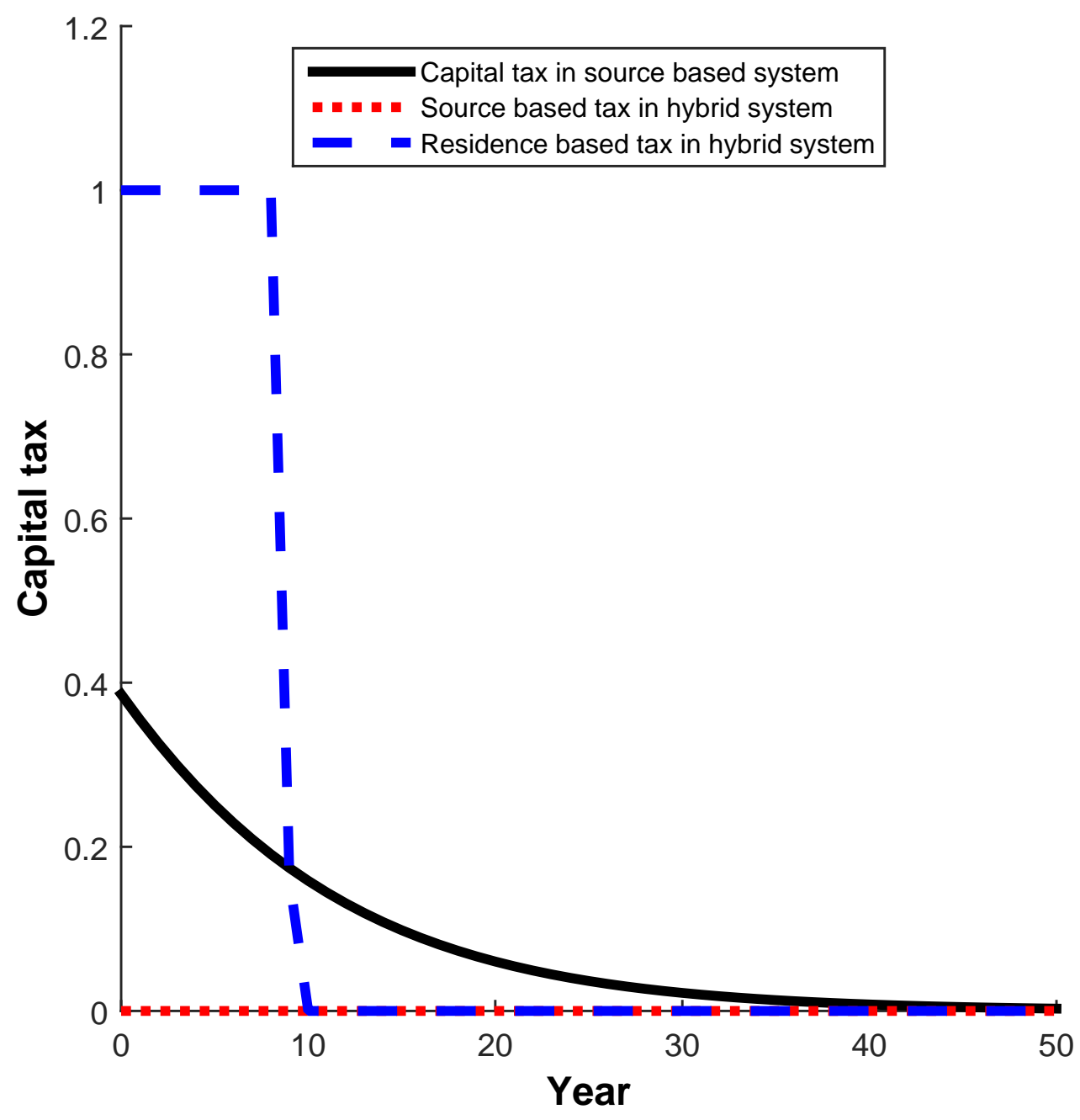


Figure 2. Externalities of source-based capital taxes in source-based and hybrid system when countries are symmetric

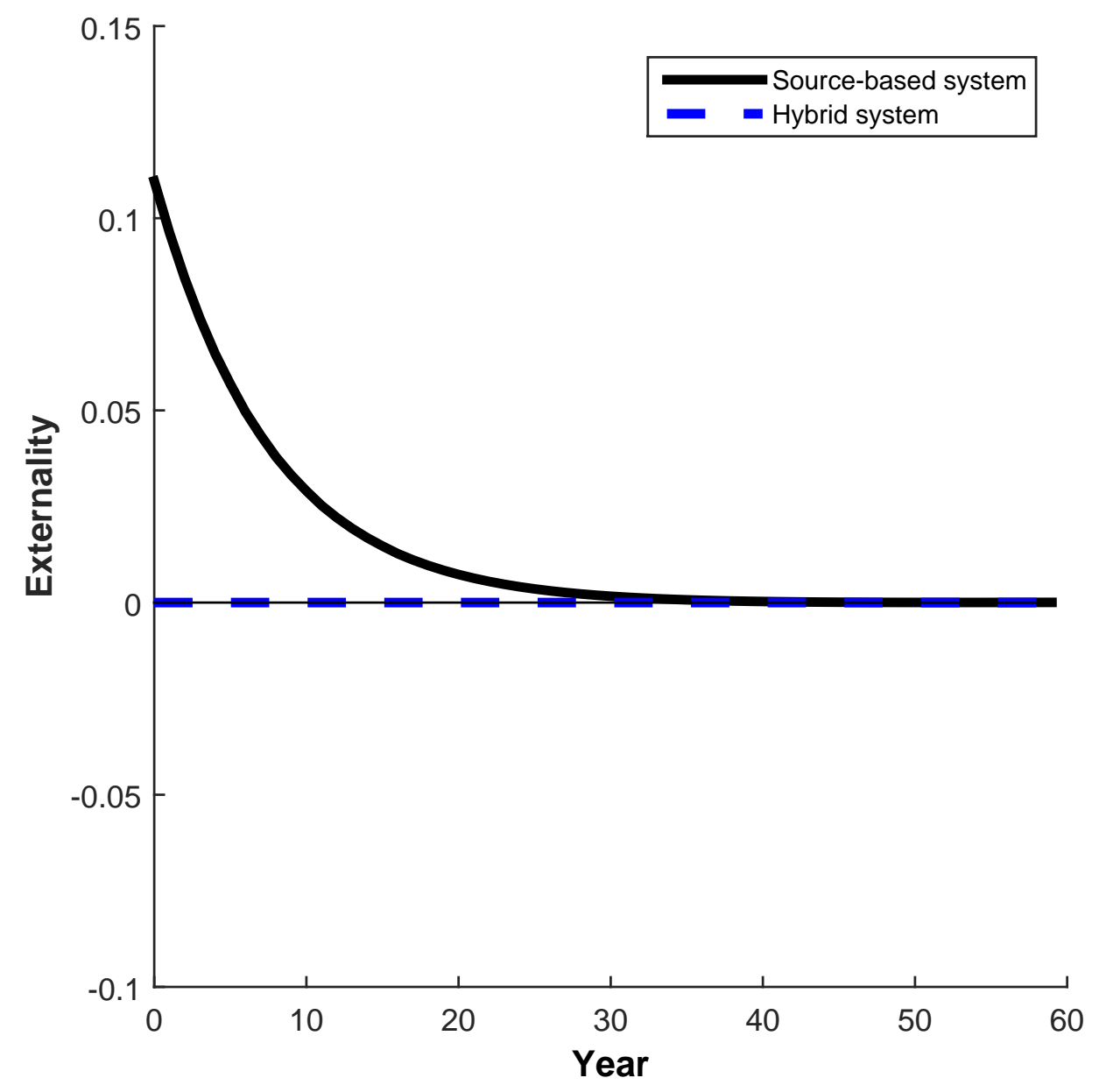


Figure 3. Government debt under the hybrid and source-based system when countries are symmetric

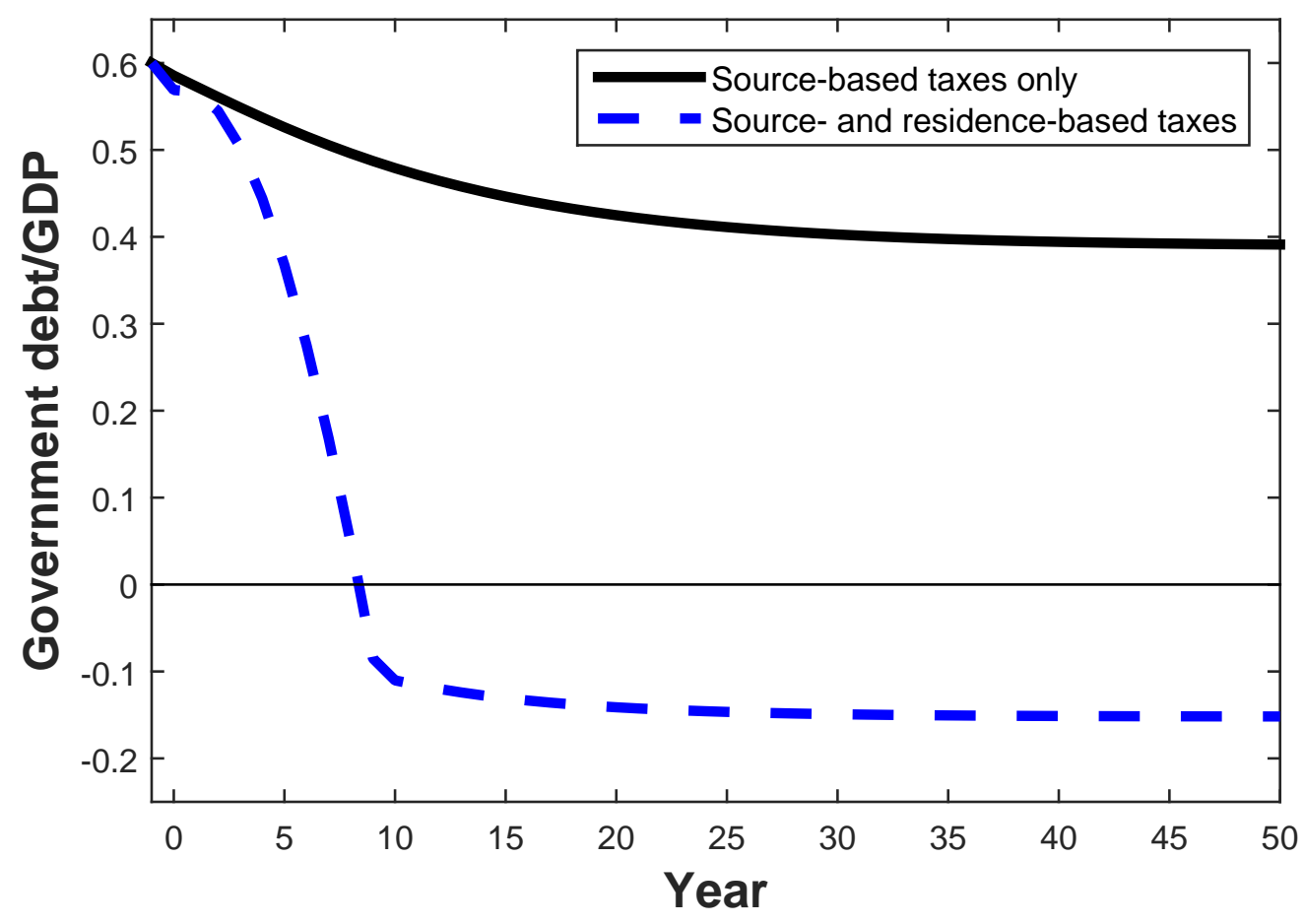


Figure 4. Capital taxes when the home country has greater initial assets

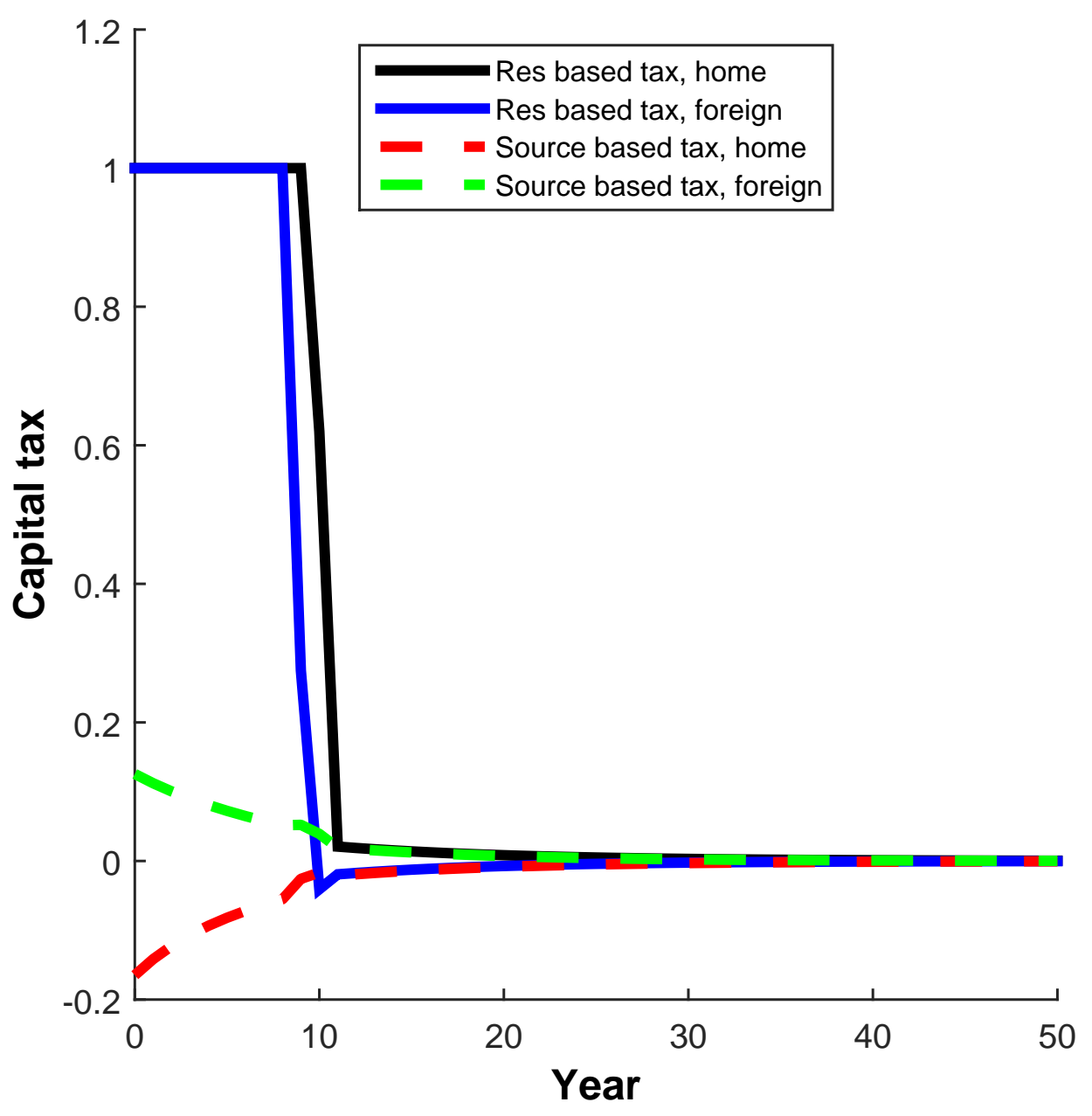


Figure 5. Externalities when the home country has greater initial assets

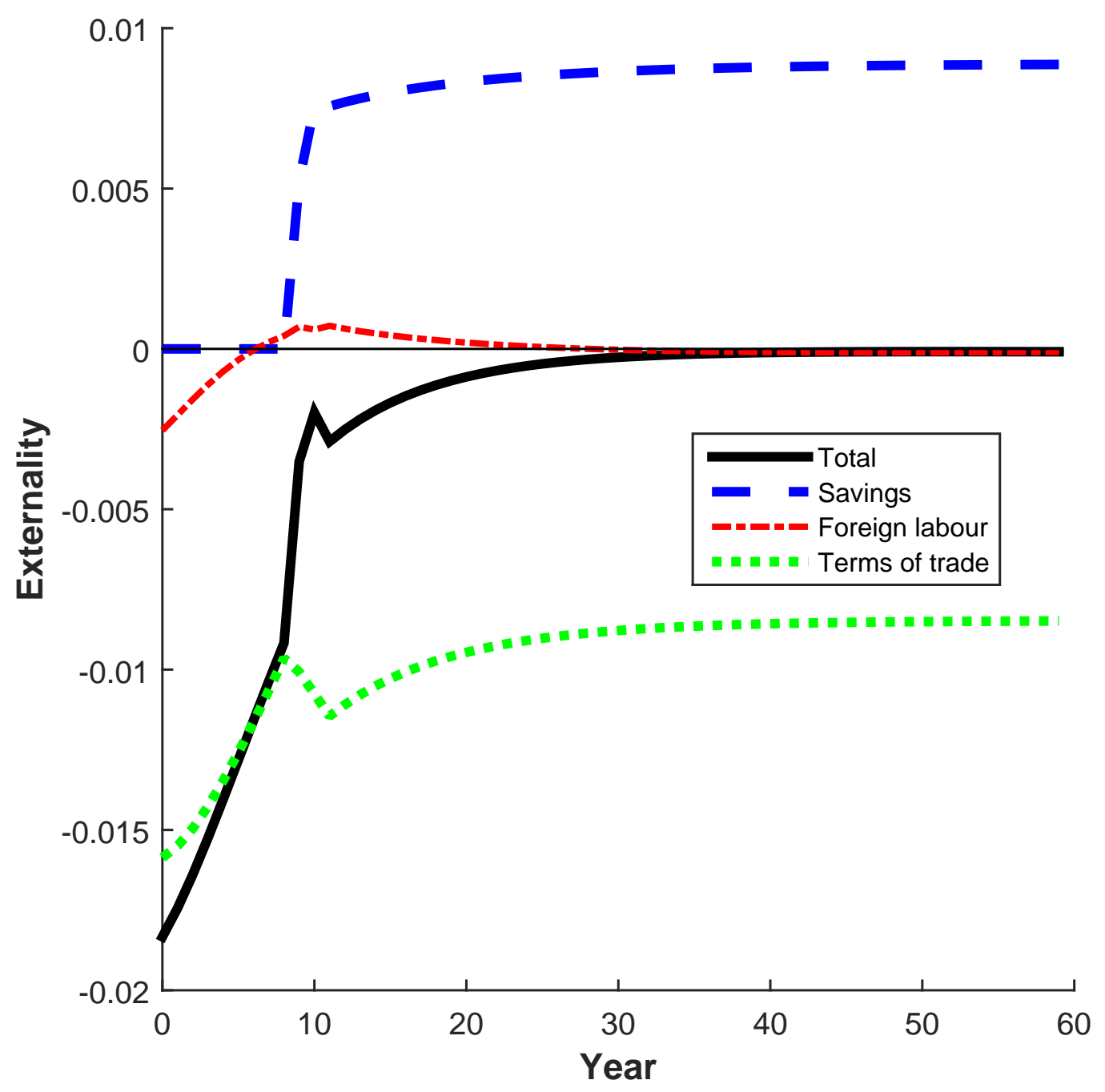


Figure 6. Capital taxes when the home country government spends less

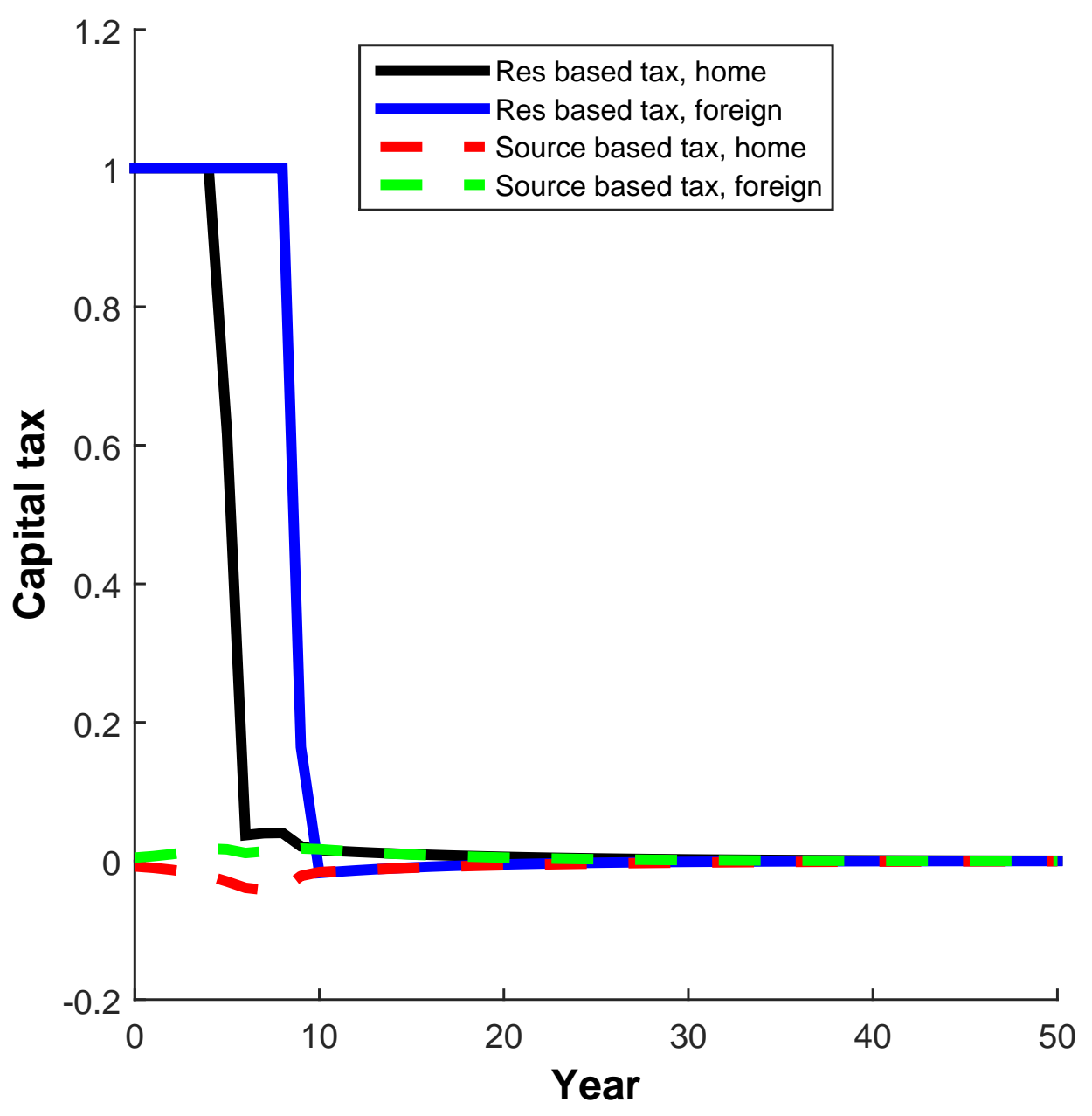


Figure 7. Externalities when the home country government spends less

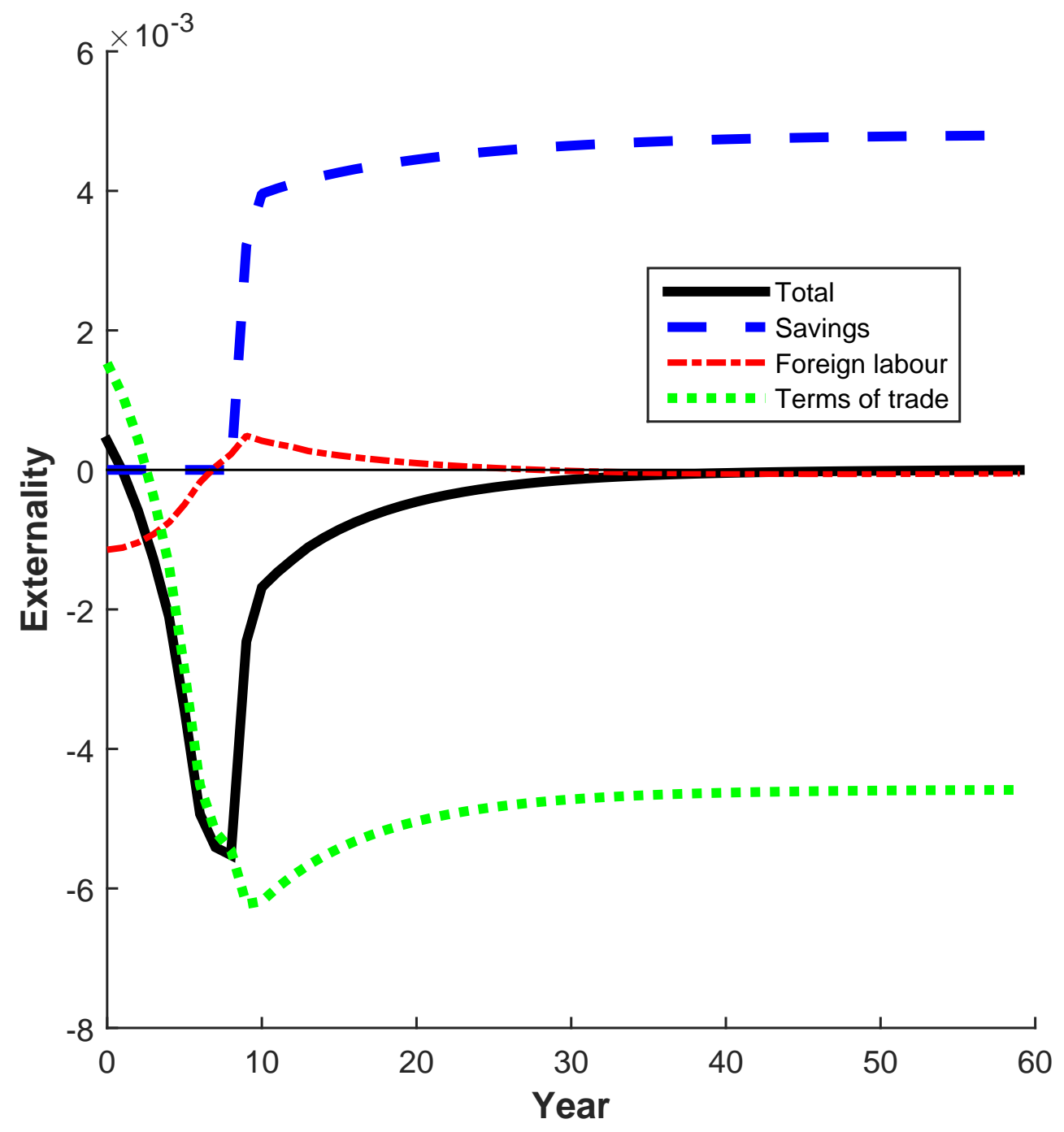


Figure 8. Capital taxes when the home country has zero initial government debt

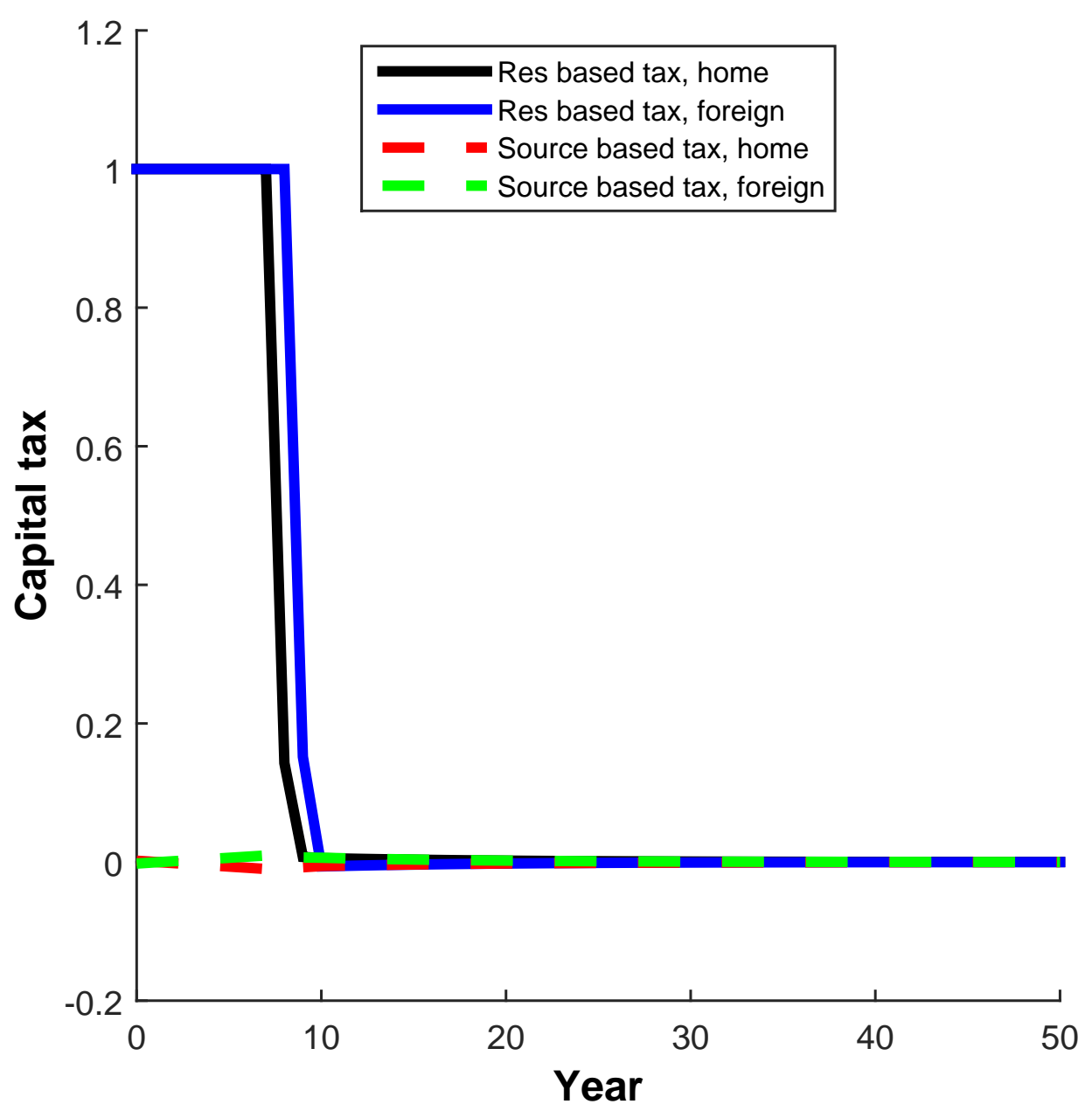


Figure 9. Externalities when the home country has zero initial government debt

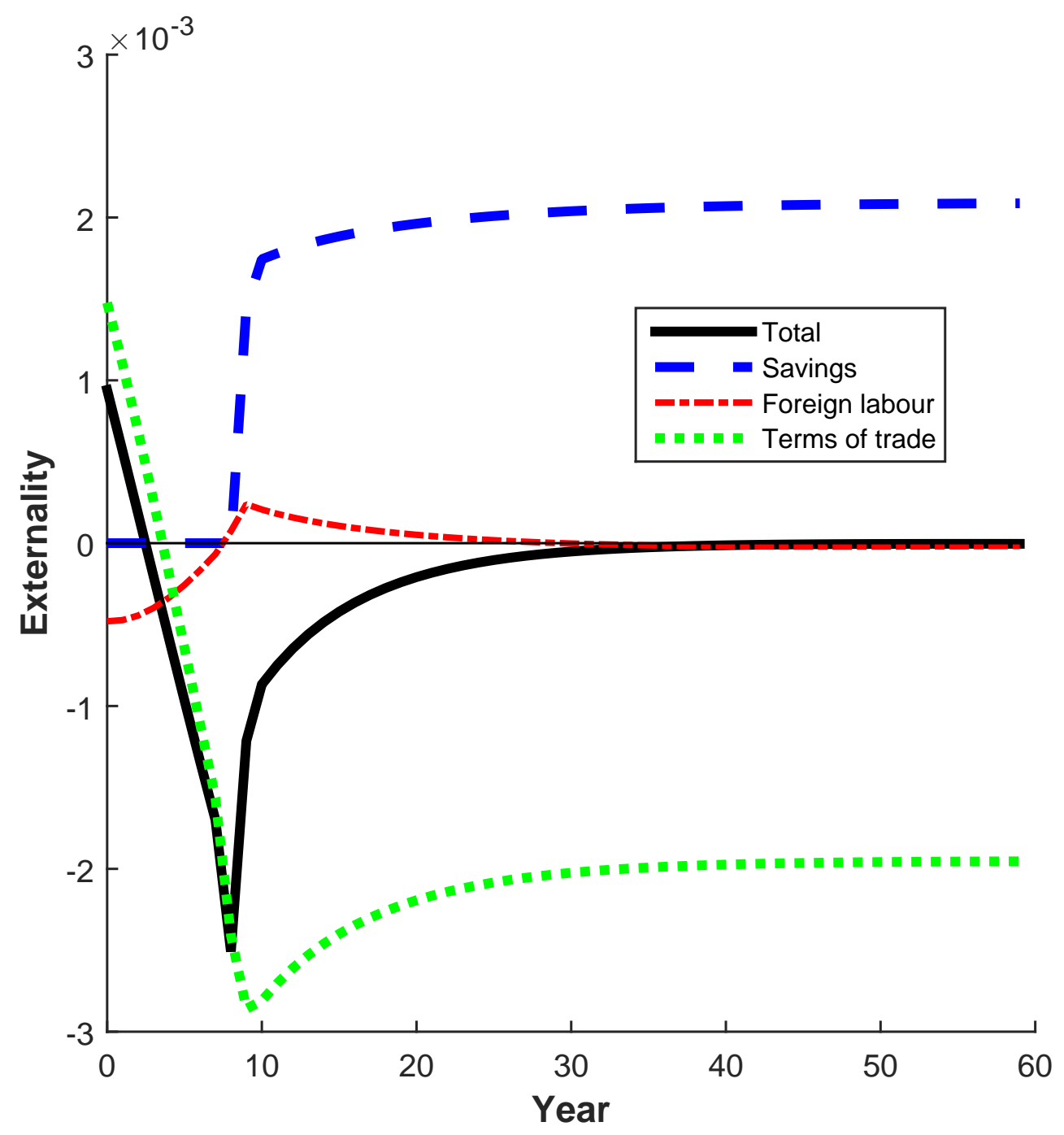


Figure 10. Capital taxes when the home country has greater population and stronger initial asset position

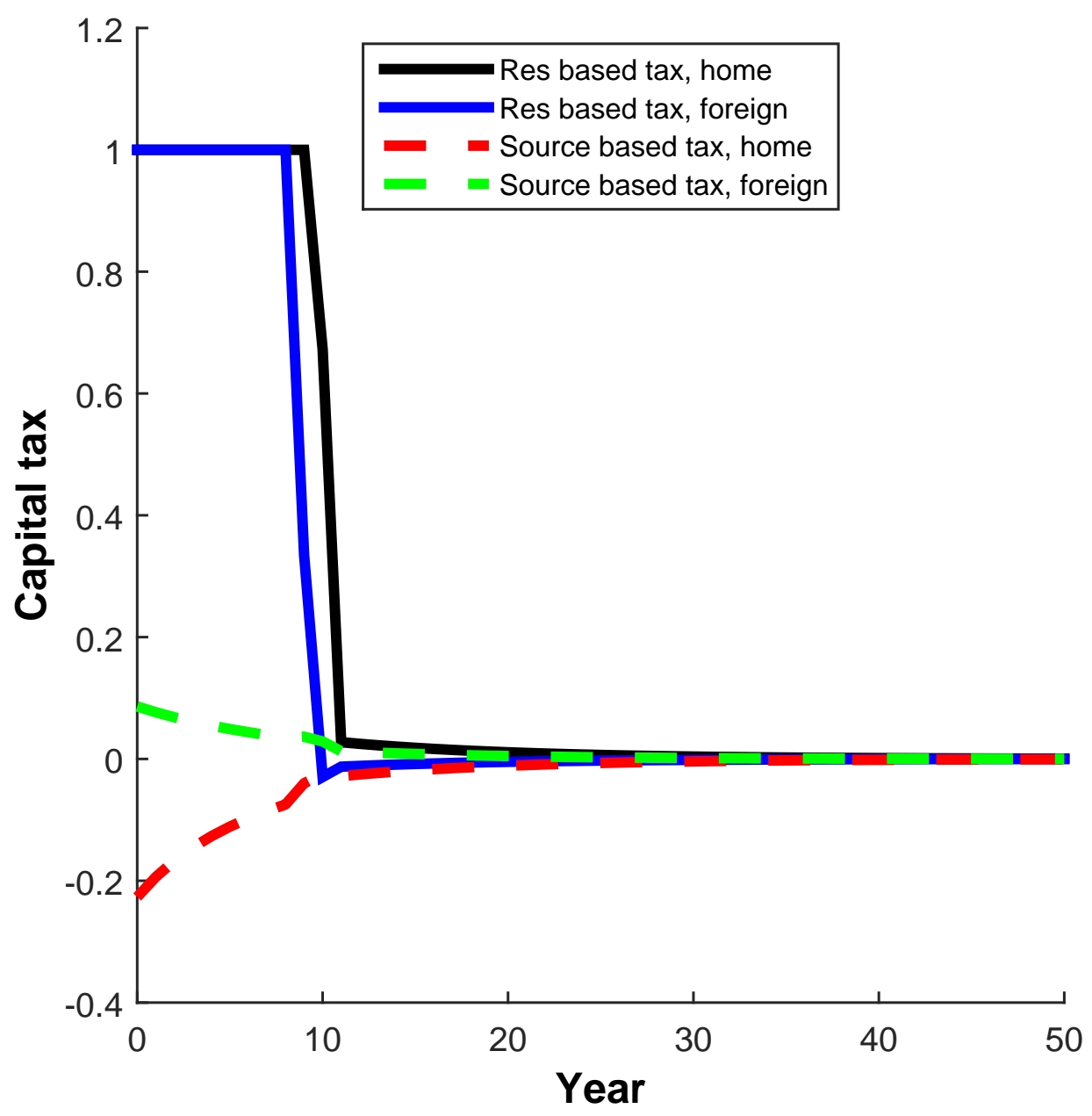


Figure 11. Externalities when the home country has greater population and stronger initial asset position

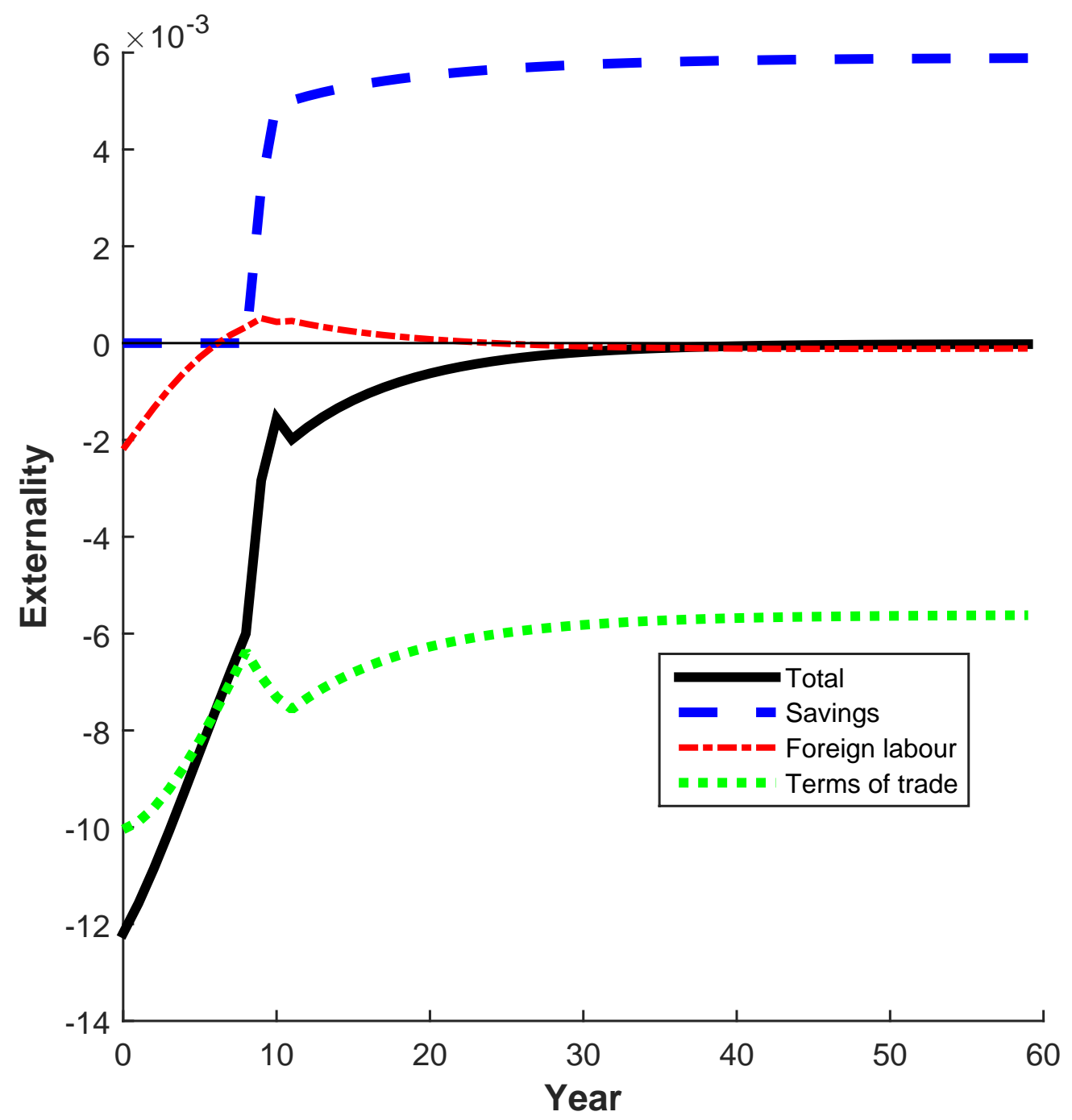




\section{References}

Aiyagari, S. R. (1995). Optimal capital income taxation with incomplete markets, borrowing constraints, and constant discounting. Journal of Political Economy 103(6), pp. 1158-1175.

Angyridis, C. (2007). Optimal capital income taxation in a small open economy. Economics Letters 95(1), 73 - 79.

Arcalean, C. (2018). Dynamic fiscal competition: A political economy theory. Journal of Public Economics 164, 211 - 224.

Arrow, K. J. and G. Debreu (1954). Existence of an equilibrium for a competitive economy. Econometrica 22(3), 265-290.

Atkeson, A., V. V. Chari, and P. J. Kehoe (1999). Taxing capital income: A bad idea. Quarterly Review, 3-17.

Baldwin, R. E. and P. Krugman (2004, February). Agglomeration, integration and tax harmonisation. European Economic Review 48(1), 1-23.

Becker, D. and M. Rauscher (2007). Fiscal competition in space and time: An endogenous-growth approach. Technical report, University of Rostock, Institute of Economics. Thuenen-Series of Applied Economic Theory 74.

Becker, J. and C. Fuest (2011). Source versus residence based taxation with international mergers and acquisitions. Journal of Public Economics 95(1), 28-40.

Bénassy-Quéré, A., N. Gobalraja, and A. Trannoy (2007). Tax and public input competition. Economic Policy 22, 385-430.

Bucovetsky, S. and J. D. Wilson (1991). Tax competition with two tax instruments. Regional Science and Urban Economics 21, 333-50.

Cai, H. and D. Treisman (2005). Does competition for capital discipline governments? Decentralization, globalization, and public policy. American Economic Review 95(3), 817-830.

Chamley, C. (1986). Optimal taxation of capital income in general equilibrium with infinite lives. Econometrica 54, 607-22.

Correia, I. H. (1996a, April). Dynamic optimal taxation in small open economies. Journal of Economic Dynamics and Control 20(4), 691-708.

Correia, I. H. (1996b, April). Should capital income be taxed in the steady state? Journal of Public Economics 60(1), 147-151. 
Dasgupta, P. S. and E. S. Maskin (2015). Debreu's social equilibrium existence theorem. Proceedings of the National Academy of Sciences 112(52).

De Pater, J. and G. Myers (1994). Strategic capital tax competition: A pecuniary externality and a corrective device. Journal of Urban Economics 36, 66-78.

Debreu, G. (1952). A social equilibrium existence theorem. Proceedings of the National Academy of Sciences of the United States of America 38(10), pp. 886-893.

Edwards, J. and M. Keen (1996, January). Tax competition and Leviathan. European Economic Review 40(1), 113-134.

Eggert, W. (2001). Capital tax competition with socially wasteful government consumption. European Journal of Political Economy 17(3), 517 - 529.

Eggert, W. and A. Haufler (1999, January). Capital taxation and production efficiency in an open economy. Economics Letters 62(1), 85-90.

Erosa, A. and M. Gervais (2002, August). Optimal taxation in life-cycle economies. Journal of Economic Theory 105(2), 338-369.

European Union (2003). Council directive 2003/48/EC of June 2003 on taxation of savings income in the form of interest payments. Official Journal of the European Union L 157/38, 26.6.2003.

European Union (2011). Council directive 2011/16/eu of 15 february 2011 on administrative cooperation in the field of taxation and repealing directive 77/799/eec. http://eur-lex.europa.eu/eli/dir/2011/16/oj.

Golosov, M., N. R. Kocherlakota, and A. Tsyvinski (2003, 07). Optimal indirect and capital taxation. Review of Economic Studies 70(3), 569-587.

Gross, T. (2014). Equilibrium capital taxation in open economies under commitment. European Economic Review 70(0), 75 - 87.

Gross, T. (2015a). On the relevance of tax competition when it is optimal to tax capital income in the long run. Carleton University Working Paper.

Gross, T. (2015b). Undistorted capital allocations and non-zero capital taxes. Carleton University Working Paper.

Gross, T. (2018). Dynamic optimal fiscal policy in a transfer union. Carleton University Working Paper.

Gross, T., P. Klein, and M. Makris (2017). Dynamic capital tax competition under the source principle. Manuscript. 
Hatfield, J. W. (2015). Federalism, taxation, and economic growth. Journal of Urban Economics 87, 114-125.

Janeba, E. and J. Wilson (1999). Tax competition and trade protection. Finanz Archiv: Public Finance Analysis 56(3/4), 459-480.

Judd, K. L. (1985, October). Redistributive taxation in a simple perfect foresight model. Journal of Public Economics 28(1), 59-83.

Keen, M. J. and C. Kotsogiannis (2002). Does federalism lead to excessively high taxes? American Economic Review 92, 363-70.

Kessler, A. S., C. Lülfesmann, and G. M. Myers (2002). Redistribution, fiscal competition, and the politics of economic integration. Review of Economic Studies 69, 899-923.

Klein, P., P. Krusell, and J.-V. Ríos-Rull (2008). Time-consistent public policy. Review of Economic Studies 75(3), 789-808.

Klein, P., V. Quadrini, and J.-V. Ríos-Rull (2005). Optimal time-consistent taxation with international mobility of capital. Advances in Macroeconomics 5(1).

Klein, P. and J.-V. Ríos-Rull (2003). Time-consistent optimal fiscal policy. International Economic Review 44(4), 1217-1245.

Kocherlakota, N. R. (2010). The New Dynamic Public Finance. Princeton University Press.

Köthenbürger, M. and B. Lockwood (2010). Does tax competition really promote growth? Journal of Economic Dynamics and Control 34(2), 191 - 206.

Kydland, F. E. and E. C. Prescott (1977, June). Rules rather than discretion: The inconsistency of optimal plans. Journal of Political Economy 85(3), 473-91.

Kydland, F. E. and E. C. Prescott (1980). Dynamic optimal taxation, rational expectations and optimal control. Journal of Economic Dynamics and Control 2, 79 - 91.

Lejour, A. M. and H. A. A. Verbon (1998). Source-based versus residence-based capital income taxes in a dynamic model. European Journal of Political Economy 14(3), 529-541.

Lockwood, B. and M. Makris (2006). Tax incidence, majority voting, and capital market integration. Journal of Public Economics 90, 1007-1025.

Lucas, R. E. and N. L. Stokey (1983). Optimal fiscal and monetary policy in an economy without capital. Journal of Monetary Economics 12(1), 55-93. 
Makris, M. (2006). Capital tax competition under a common currency. Journal of Urban Economics 59(1), 54-74.

Mendoza, E. G. and L. L. Tesar (2005, January). Why hasn't tax competition triggered a race to the bottom? Some quantitative lessons from the EU. Journal of Monetary Economics 52(1), 163-204.

Nash, J. F. (1950). Equilibrium points in N-person games. Proceeding of the National Academy of Sciences USA 36, 48-49.

Nicodème, G. (2006, June). Corporate tax competition and coordination in the european union: What do we know? Where do we stand? European Economy, Economic Papers 250, European Commission.

OECD (1998). Harmful tax competition - an emerging global issue. Technical report, OECD Committee on Fiscal Affairs.

OECD (2017). Standard for Automatic Exchange of Financial Account Information in Tax Matters, Second Edition. OECD Publishing, Paris.

OECD (2018). Standard for Automatic Exchange of Financial Information in Tax Matters, Implementation Handbook, Second Edition. OECD Publishing, Paris.

Quadrini, V. (2005). Policy commitment and the welfare gains from capital market liberalization. European Economic Review 49(8), 1927 - 1951.

Razin, A. and E. Sadka (1991, September). International tax competition and gains from tax harmonization. Economics Letters 37(1), 69-76.

Straub, L. and I. Werning (2020, January). Positive long-run capital taxation: Chamley-Judd revisited. American Economic Review 110(1), 86-119.

Wildasin, D. E. (2003, October). Fiscal competition in space and time. Journal of Public Economics 87(11), 2571-2588.

Wilson, J. D. (1986, May). A theory of interregional tax competition. Journal of Urban Economics 19(3), 296-315.

Wilson, J. D. (1999). Theories of tax competition. National Tax Journal 52, 269-304.

Wilson, J. D. and D. E. Wildasin (2004, June). Capital tax competition: bane or boon. Journal of Public Economics 88(6), 1065-1091.

Wooders, M., B. Zissimos, and A. Dhillon (2007). Tax competition reconsidered. Journal of Public Economic Theory 9, 391-423. 
Zodrow, G. R. (2010). Capital mobility and capital tax competition. National Tax Journal 63(4), 865-901.

Zodrow, G. R. and P. Mieszkowski (1986, May). Pigou, Tiebout, property taxation, and the underprovision of local public goods. Journal of Urban Economics 19(3), 356-370. 